\title{
LAS CONSTITUCIONES DE LOS ESTADOS FEDERADOS; EN PARTICULAR LAS DE LOS ESTADOS NORTEAMERICANOS
}

\author{
M. ${ }^{a}$ ESTHER SEIJAS VILLADANGOS \\ Catedrática de Derecho Constitucional \\ Universidad de León
}

\begin{abstract}
SUMARIO
I. Las constituciones estatales: las grandes olvidadas de los procesos federalizadores. II. Marco comparado de las constituciones estatales como contexto de un estudio de Derecho constitucional particular: las constituciones de los estados norteamericanos. III. El surgimiento de las constituciones estatales. IV. Carácter normativo o programático de las constituciones estatales ¿Estamos ante auténticas constituciones? V. Estructura y contenido de las constituciones estatales. VI. La reforma de las constituciones estatales. VII. Los avatares del proceso constitucional estatal y sus enseñanzas para un futurible proceso de federalización y constitucionalización estatal en España.
\end{abstract}

\section{LAS CONSTITUCIONES ESTATALES: LAS GRANDES OLVIDADAS DE LOS PROCESOS FEDERALIZADORES}

La ilusión federal ha jalonado la vida académica y política preocupada de la organización territorial, viendo en esa fórmula un patrón magistral para la solución de conflictos con plasmación territorial. Así, Tarlton sostenía que «el concepto de federalismo ha sido la mayor panacea del pensamiento político occidental para una serie increíble de conflictos.... Cuando nos topamos con acontecimientos que han demandado cooperación y coordinación, mientras otros intereses y posiciones han pugnado por la preservación de la diferencia y de la diversidad, la respuesta ha recaído inexcusablemente de la mano de una solución federal» ${ }^{1}$. La

1 Tarlton, Ch. D.: Symmetry and asymmetry as elements of federalism: a theoretical speculation. The Journal of Politics 27.4, 1965, p. 874. En esa devoción federal también podemos referenciar a DuCHACEK, I: Comparative federalism: the territorial dimensión of politics. Philadelphia, University Press of America, 1987, p. 191. 
realidad ha demostrado que la fórmula federal también fracasa y el federalismo no es un remedio infalible ${ }^{2}$.

La problemática de la organización territorial en España se ha aferrado al federalismo como la principal balsa para superar la tensión arraigada ${ }^{3}$. En esta tendencia no podemos obviar los informes que se han elaborado avalando tal opción, una especie de hoja de ruta: el Manifiesto de los cien (2018), inicialmente ideado por Alberto López Basaguren ${ }^{4}$, Ideas para una reforma de la Constitución ${ }^{5}$, Por una reforma constitucional federal $(2013)^{6}$, que aporta la idea de asumir un cambio constitucional en los Estatutos de autonomía desde el sugerente presupuesto de que «los Estatutos dejan de tener como misión principal la asunción de las competencias autonómicas. Este hecho altera la naturaleza de estas normas, que pueden pasar a configurarse como la «Constitución» de la Comunidad Autónoma». Por acotar esta relación, la Fundación Alfonso Perales (2012) promovería Por una reforma federal del Estado autonómico ${ }^{7}$. En este documento, como en los demás citados, se ensalza la fórmula federal, pero se presta exigua atención a uno de los aspectos más conflictivos en la misma, como es la constitucionalización de las unidades estatales federadas.

$\mathrm{Y}$ es que las constituciones de los Estados federados son las grandes ignoradas de los modelos federales, tanto por los ciudadanos ${ }^{8}$ como por el exiguo interés

2 Watts, R., «Daniel J. Elazar: Comparative Federalism and Post-Statism», Publius Vol. 30, No. 4, Essays in Memory of Daniel J. Elazar (Autumn, 2000), pp. 155-168. «Federation is not a panacea for those seeking to reconcile ethnic». Erk, J. y Anderson, L., «The Paradox of Federalism: Does Self-Rule Accommodate or Exacerbate Ethnic Divisions?» Regional E Federal Studies, 2009, 19:2, 191-202. «Federalism is not a panacea for conflict».

3 En otros trabajos nos hemos detenido de forma minuciosa a estudiar esa reforma federal, incluyendo prerrequisitos, elementos formales y consecuencias de esa transición federal, a partir del neologismo de «grado de federalidad de un Estado». Cfr. Seijas Villadangos, M.E., «Crisis, federalidad, cultura federal y federalismo asimétrico: odisea constitucional 2013», Revista General de Derecho Constitucional, n. ${ }^{\circ}$. 16, 2013, pp. 9-32; «Significado de los nuevos derechos en el proceso de eventual federalización del modelo autonómico: El grado de federalidad del Estado español» en Matia Portilla, Francisco Javier, (coord.) Pluralidad de ciudadanías, nuevos derechos y participación democrática, Madrid, CEPC, 2011, pp. 257-283 o «Federalismo resiliente: vanguardia y retaguardia de una nueva organización territorial del Estado español», Ruiz-Rico Ruiz, G., Porras Nadales, A., Revenga Sánchez, M., Regeneración democrática y reforma constitucional, Valencia, Tirant, 2017, pp. 305-344.

4 Federalismo frente a ruptura. El manifiesto de los 100. (https://federalistesdesquerres.org/es/2018/09/ federalismo-frente-a-ruptura-manifiesto-de-los-100/)

5 En el punto 13 de tal propuesta se sostiene que «ante esta situación, debemos abordar la reforma del modelo territorial basándonos en las técnicas del federalismo, pero sin darle excesiva importancia al término con el que se califique al Estado» Accesible en : http://idpbarcelona.net/docs/actual/ideas_reforma_constitucion.pdf

6 Accesible en https://fcampalans.cat/uploads/publicacions/pdf/164_papersdelafundacio_def.pdf

7 Cámara Villar, G., Por una reforma federal del Estado autonómico. Sevilla, Fundación Alfonso Perales, 2012. «La aprobación de sus normas institucionales básicas (Constituciones) no requiere una participación de los órganos legislativos federales. Únicamente están sometidas a un control de constitucionalidad conforme a ciertos criterios que dotan de homogeneidad al conjunto» (p. 58).

8 «Cuando la mayoría de los americanos piensan en el derecho constitucional de su país su mente naturalmente se fija en el documento escrito que fue diseñado por la Convención de $1787 \ldots$... Olvidando que cuando los Padres de la Constitución se reunieron en Filadelfia ya tenían ante sus ojos las constituciones 
que han suscitado en la academia, a lo que cabría agregar las reticencias jurisprudenciales a su aplicación y reconocimiento. Una característica esencial de los sistemas federales es la dualidad constitucional. La conformación de estados federados como unidades constitucionales con plena autonomía, lo que les conduce a dotarse de una constitución, es la singularidad medular del federalismo y de todo Estado federal. A partir de ahí, se desarrolla un derecho constitucional ex novo, cuyo máximo exponente es la constitución del estado federado. Y es que «un observador, con nada frente a él más que los textos de estas constituciones, podría aprender mucho acerca de la política estatal, las leyes estatales y la vida social»9 de un estado federado, y con ello de la totalidad de ese Estado. Este desequilibrio entre su importancia y su percepción y recepción es el motivo de esta atención, insertada en un marco de reflexión más amplio que tiene como objetivo el análisis de las dificultades de implementar el federalismo en un Estado, como España. A sus particularidades dedicaremos nuestra atención, una mirada más profunda que ahonda en la complejidad que agrega un proceso constituyente estatal múltiple dentro de un potencial proyecto de federalización de un Estado. La dialéctica de base radica en plantear si, a la luz de lo analizado, servirían los vigentes Estatutos de Autonomía como constituciones estatales solo suprimiendo el aspecto formal de su aprobación final por el legislativo central, incluso anticipando el diseño de una Constitución federal ${ }^{10}$, o es preciso un proceso constituyente múltiple ex novo, sobre el que resultaría útil verificar qué acaece en el constitucionalismo estatal norteamericano. En otras palabras, los problemas concretos de una reforma federal.

La importancia de estudiar el constitucionalismo estatal se incrementa al verificar que sobre él se produce una influencia del constitucionalismo federal (federalismo vertical) y que, a su vez, el constitucionalismo estatal, se influye entre sí (federalismo horizontal). Esta circunstancia se constará internamente en el caso de los Estados Unidos, pero cabe la posibilidad de esperar que esta «polución estatal» transcienda las fronteras federales y sus efectos se proyecten a escala internacional (federalismo global ${ }^{11}$ ).

La metodología de este estudio será de carácter inductivo. A partir de un esbozo desde un marco comparado, se erigirá un estudio de Derecho Constitucional particular, con epicentro en las constituciones de los Estados norteamericanos. Su implementación tomará como base dichas constituciones, particularmente

escritas de 13 estados independientes». Morey, W., «The first State Constitutions», Annals of the American Academy of Politics and Social Science, Vol. 4, sept. 1893, p. 1.

9 Friedman, L., A history of American Law, 2. ${ }^{a}$ ed., Nueva York, Simon \& Schuster, 1985, p. 120.

10 Cfr. Montilla Martos, J.A., Reforma federal y Estatutos de segunda generación como modelo para la reforma federal de la Constitución, Cizur Menor, Aranzadi, 2015, pp. 19-74

11 Gamper, A., «A global theory of federalism: the nature and challenges of a federal State», German Law Journal, Vol 6, n. ${ }^{\circ}$ 10, 2005, pp. 1297-1318. Enfatiza un «creciente discurso global» sobre el federalismo, que trasciende la comparación o la internacionalización del concepto y de sus elementos, en este caso las constituciones estatales. (p. 1318). 
concretas aportaciones e ilustraciones específicas en torno a diferentes cuestiones suscitadas, con la finalidad de concluir en la articulación de una dogmática, síntesis unificadora de los elementos de conexión entre la pluralidad que es la constitución de un estado federado, puesto que «a pesar de su diversidad, las constituciones estatales americanas comparten ciertos aspectos comunes» ${ }^{12}$, lo que llevará a hablar de un modelo de constitución estatal que incluso se perfilaría en los años veinte de la pasada centuria por la Liga Municipal Nacional norteamericana ${ }^{13}$. Por su cantidad, por su variedad y por su longeva consolidación se ha optado por acotar el trabajo a dichas constituciones. Sobre ese planteamiento se articulará la estructura del trabajo con un objetivo meridianamente claro que es evidenciar la antinomia entre la escasa importancia prestada a las constituciones estatales y su carácter complejo, poliédrico y decisivo para la vida de una federación, especialmente desde los Estados Unidos.

\section{MARCO COMPARADO DE LAS CONSTITUCIONES ESTATALES COMO CONTEXTO DE UN ESTUDIO DE DERECHO CONSTITUCIONAL PARTICULAR: LAS CONSTITUCIONES DE LOS ESTADOS NORTEAMERICANOS}

Un mapa territorial de las constituciones estatales nos lleva a fijar nuestra atención en diferentes puntos del globo. Son catorce los sistemas federales que permiten que sus unidades subnacionales adopten constituciones estatales: Alemania, Argentina, Austria, Australia, Brasil, Estados Unidos, Etiopía, Iraq, Malasia, Méjico, Rusia, Sudáfrica, Suiza y Venezuela ${ }^{14}$. En el siguiente epígrafe queremos plasmar una selección de los referentes doctrinales más relevantes que se han ocupado del estudio de las constituciones estatales, con un punto y aparte sustantivo para el caso canadiense, por la singularidad que este supone. Por consiguiente, más allá del formato, y a veces ni compartiendo el mismo significante,

12 Tarr, G.A., State Constitutions for the twenty-first century. The Agenda of State Constitutional Reform, Albany, State University of New York Press, 2006, p. 1.

13 NATIONAL MUNICIPAL LEAGUE. COMMITTE ON STATE GOVERNMENT, A model State Constitution. New York, National Municipal League, 1924. Este modelo de Constitución fue publicado originariamente en 1921, teniendo sucesivas ediciones 1928, 1933, 1941, 1948 hasta 1968 en que se publicó una sexta edición. Su contenido ha ido variando en las secciones, pero teniendo como artículos principales los referidos a una Carta de Derechos, sufragio y elecciones, iniciativa y referéndum, poder ejecutivo, poder judicial, financiación, administración local, gobierno, empleo público, bienestar, relaciones intergubernamentales, y revisión constitucional. Cfr. Graves, G.B., «Fourth Edition of the Model State Constitution», American Political Science Review, Vol. 35, Issue 5, October 1941, pp. 916-919.

14 Marshfield, J.L., «Models of subnational constitutionalism», Penn State Law Review, Vol. 115: 4 , p. 1158. Dejamos fuera de esta relación a federaciones como India donde solo un estado, Kashmir, está autorizado por el art. 370 de la Constitución india a tener su propia constitución. KAHN, H., «Federalism and non territorial minorities in India», TARr, A., Williams, R.F., y MARKo, J., Federalism, subnational constitucions and minority rights, London, Praeger, 2004, p. 201. 
nos encontramos con un panorama complejo que, desde el punto de vista académico, tiene las siguientes inexcusables referencias.

\section{II.1. Referencias doctrinales en el estudio de las Constituciones estatales}

A nivel comparado debemos hacer mención a la existencia de un grupo de investigación sobre constituciones subnacionales ${ }^{15}$ en Estados federales y cuasi federales dentro de la Asociación internacional de Derecho Constitucional, cuya formación se remonta a 2004 a partir de una conferencia en la Rockefeller Foundation's Conference Center, en Bellagio (Italia) con el título «Subnational Constitutions and Federalism: Design and Reform», en la actualidad liderado por Robert Williams y Patricia Popelier. Si pensamos en Estados Unidos y en una perspectiva comparada, dos nombres y un lugar son el epicentro doctrinal esencial: Alan Tarr y Robert Williams, el lugar común a ambos es el Center for State Constitutional Studies, en la Rutgers University en Candem, Estado de Nueva Jersey. A ellos podemos unir como referentes, entre otros, los nombres de John Dinan o Jonathan Marshfield.

En Australia debemos de atender a la obra de Cheryl Saunders ${ }^{16}$, de la Melbourne Law School, sin descuidar los trabajos de Nicholas Aroney, de la Universidad de Queensland o Alan Fenna de Curtin University, siendo las obras de referencia The constitutions of the Autraliann States, de Richard Darrell Lumb ${ }^{17}$ y The Constitutional Systems of the Australian States and Territories, de Gerard Carney ${ }^{18}$. Los seis estados australianos tienen su propia constitución (Constitución de Nueva Gales del Sur de 1902, Constitución del Estado de Victoria de 1975, Constitución de Tasmania de 1934, Constitución de Australia Occidental de 1889/1975, Constitución de Australia del Sur de 1855/1934 y Constitución de Queensland 1867/2001 —todas accesibles en Australasian Legal Information Institute, http://www8.austlii.edu.au/_-), aunque no se les confiera un elevado protagonismo en el diseño jurídico de la federación.

En el caso alemán, la consolidación de las constituciones de los Länder en el marco jurídico es incuestionable, siendo objeto de un interesante trabajo doctrinal que nos remite a la obra de Stern, Starck o Stiens, pero, sobre todo, en castellano, al interesante trabajo de Sonsoles Arias Guedón, Las constituciones de los Länder de la República Federal de Alemania. En Alemania el constitucionalismo dual federal habilita la coexistencia de la Constitución federal Grundgesetz, de

15 La expresión de constituciones subnacionales es usada frecuentemente por la doctrina: WiLLIAMS, R., «Alaska, the last statehood constitution, and subnational rights and governance», Alaska Law Review, Vol. 35:2, 2018, p. 141.

16 Saunders, CH., «Australian State Constitutions», Rutgers Law Journal, n. ${ }^{\circ} 31,1999$.

17 University of Queensland Press, St. Lucia Qld, 1991 (5. a edición).

18 Cambridge University Press, Port Melbourne, 2006. 
1949, y dieciséis constituciones de los Länder. Su consolidación y proximidad nos acercan a una problemática que se magnifica desde la perspectiva norteamericana.

Sin agotar la posible casuística, otras referencias doctrinales nos llevarían a Brasi $^{19}$ o Argentina ${ }^{20}$ donde el estudio del constitucionalismo estatal está ocupando un protagonismo relevante en la academia.

\section{II.2. Las no-constituciones provinciales canadienses}

En el caso de Canadá hemos de advertir que no existen constituciones provinciales formales ${ }^{21}$, sino que estas lo son en el sentido material del término, al modo y manera de Reino Unido, Israel o Nueva Zelanda, consistiendo en una serie de disposiciones legales referidas a la regulación de los poderes $(v . g r$. Legislature Act, Executive Act), de los derechos ( $v$ gr. Human Rights Act) o de las actuaciones de los mismos ( $v$. gr. Election Act), así como referidas a convenciones constitucionales, (v. gr. el gobierno debe dimitir o solicitar la disolución de la cámara cuando prospera una moción de censura $)^{22}$, pero sin ostentar la denominación de Constitución de la Provincia de.... ni derivar una posición jerárquica superior a la de otras normas provinciales. Esto supone considerar a Canadá como «un caso aparte», o una «anomalía» ${ }^{23}$ en el marco federal en lo que concierne a este aspecto particular de las constituciones de los estados federados o constituciones subnacionales ${ }^{24}$. La contradicción entre la fortaleza política de las provincias canadienses y su fragilidad constitucional, dado que ninguna de ellas tiene

19 Bajo la denominación de Constate (https://constate.org/), se conmemora en 2019, los 30 años de vigencia de las constituciones estatales brasileñas. Da Cunha Ferraz, A.C., O poder constituinte dos Estados membros, Revista dos Tribunais, 1979; Ferrari, S., Constituição estadual e federação, Rio de Janeiro, Lumen Juris, 2003; GonÇALves Couto, C., «Imitação ou coerção? Constituições estaduais e centralização federativa no Brasil», Revista de administração pública, 52(2) 2018:321-344.

20 Bidart Campos, G., Tratado elemental de Derecho Constitucional argentino, Buenos Aires, ed. Ediar, 1993; Noriega, J., «Las provincias argentinas en la organización del Estado federal», Rev. In Iure, año 2, Vol I, La Rioja (Argentina), 2012, pp. 1-15; SABSAY, D. «El frustrado intento de reforma de la Constitución de la ProvinciadeBuenos Aires» (http://e-spacio.uned.es/fez/eserv/bibliuned:Derechopolitico-1991-34-1A0C5521/ PDF). FríAs, P., Las nuevas constituciones provinciales, Buenos Aires, Editorial Depalma, 1989.

21 Morin, J.J., «Pour una nouvelle constitution du Québec», McGill Law Journal, Vol. 28, n. ${ }^{\circ}$ 2, p. 173.

22 Sobre el contenido diversificado de las constituciones provinciales véase: Rowe, M. y CoLLINS, J.M., "What is the Constitution of a Province», Dunn, C., Provinces: Canadian Provincial Politics, Toronto, University of Toronto Press, 2016, pp. 297-314.

23 Morton, F. L., «Provincial constitutions in Canada», 17 de mayo de 2004. Conferencia en Rutgers Law School. https://statecon.camden.rutgers.edu/sites/statecon/files/subpapers/morton.pdf. A esa singularidad canadiense habría que agregar el no disponer de un Senado elegido por las provincias, confirmando la tesis de que cada federación, incluso las que actúan como patrón o referente, tampoco siguen un modelo ideal federal, si es que este existiese.

24 Williams, R., «Teaching and researching comparative subnational constitutional law», Cuadernos de Federalismo XXVI, Córdoba, Academia Nacional de Derecho y Ciencias Sociales, 2013, pp. 143-169. 
una constitución escrita, con una salvedad, merece también una explicación. La contextualización de esta situación peculiar se enmarca en la tradición británica de constitucionalismo no escrito, de la que por otro lado se apartaría su vecino del sur. Las cuatro colonias que impulsaron la, primero, confederación y, luego, federación canadiense se regían en 1867 por un compendio normativo que aunaba legislación británica y colonial, junto con Proclamaciones reales, cartas y elementos procedentes de las convenciones constitucionales y de la costumbre como fuente jurídica. La British North America Act, 1867 (Parte V) en sus arts. 58-90 reconoce expresamente la figura de las Constituciones provinciales ${ }^{25}$, a cuyos legislativos confiere un poder de reforma en régimen de exclusividad, con la única excepción del Gobernador, Lieutenant Governor, representante de la Reina. Bajo esta potestad, por ejemplo, las provincias han suprimido de modo unilateral la segunda cámara de sus legislativos. Esa facultad se reafirma en el art. 45 de la constitución canadiense de $1982^{26}$. En el momento de diseñarse el Dominio canadiense surgieron algunas voces que abogaban en pos de que cada provincia «se dotase de una constitución escrita, comportando para cada legislativo la obligación de obedecer sus mandatos que de otro modo serían anulados por un tribunal creado ad hoc» ${ }^{27}$. La realidad fluyó por distintos derroteros.

La única provincia canadiense que se aparta, a su vez, de esta dinámica común - excepción a la excepción — es Columbia Británica, que dispone de una Constitution $A c t^{28}$, del año 1996, que regula las instituciones del poder legislativo y ejecutivo en la provincia y que expresamente declara (art. 2) que está sujeta a la Constitución federal/nacional, Constitution Act, 1867. Este dato no ha dudado en catalogarse como «el extraño caso de una Constitución Provincial» ${ }^{29}$.

En este terreno de las singularidades, también hemos de citar el caso de la Provincia de Alberta, que sin apartarse de la acepción westminsteriana de constitución no escrita, ha procedido a reunir, en una especie de texto refundido — por utilizar una expresión afín a nuestro bagaje constitucional- una serie de disposiciones que no son una lista definitivamente cerrada por la naturaleza del

25 Los artículos 58-68 regulan el poder ejecutivo de cada provincia que pivota en torno a un Vicegobernador, Liutenent Governor. A partir del art. 69 se regula el poder legislativo, con menciones específicas a Ontario (arts. 69-70); Quebec (arts. 71-80); Ontario y Quebec (arts. 82-87); Nueva Escocia y Nuevo Brunswick (art. 88) y las cuatro provincias (art. 90). Estos artículos no serían susceptibles de ser reformados por el art. 45, de modo exclusivo por cada provincia.

26 Este precepto es el contrapunto del art. 41 de la Const. de 1982 donde se exige la unanimidad provincial para la reforma de cuestiones vinculadas a la Reina, el Gobernador General o los Tenientes Gobernadores Provinciales, la garantía de la misma representación provincial en la Cámara Baja y Alta, la cuestión lingüística, la composición del Tribunal Supremo y la misma reforma del art. 41.

27 Taché, J.C., Des provinces de l'Amérique du Nord et d'une union fédérale, Québec, Brousseau, 1858, p. 187. Disponible en la Biblioteca Nacional de Quebec (http://bibnum2.banq.qc.ca/bna/numtexte/59062.pdf)

28 http://www.bclaws.ca/civix/document/id/lc/statreg/96066_01

29 Sharman, C., «The Strange Case of a Provincial Constitution: The British Columbia Constitution Act», Canadian Journal of Political Science / Revue canadienne de science politique, Vol. 17, No. 1 (1984), pp. $87-108$. 
formato. En ese listado destaca la Alberta Act, 1905, que se ha agregado como apéndice a la Constitution Act, 1982 de toda la Federación canadiense. Es precisamente la posibilidad conferida en la reforma constitucional canadiense de 1982 acerca de que las provincias aprueben leyes que explícitamente formen parte de su constitución provincial «constitution of the province» ${ }^{30}$, lo que se hizo merced a The Constitution of Alberta Amendment Act, 1990, cuyo contenido se dedica a consolidar el status protegido y singular de los «métis», un pueblo aborigen radicado en Alberta (http://albertametis.com/). El descontento de Alberta con su posición en la federación canadiense ha reabierto episódicamente las propuestas de proseguir en la línea de reformar la constitución para fortalecer su autonomía y redefinir las relaciones provinciales con la federación (v. gr. El informe y las recomendaciones del MLA Committe on Strengthening Alberta's role in Confederation, $\left.2004^{31}\right)$.

El caso de Quebec ${ }^{32}$ solo alberga la singularidad de los futuribles ${ }^{33}$, esto es la voluntad política por parte de los partidos nacionalistas y soberanistas de dotarse de una "constitution québécoise», que, no obstante, ha estado presente en la historia de Quebec como glosa Turpin ${ }^{34}$. Estas propuestas tuvieron su punto álgido en el proceso electoral de 2007. Previamente la Action Démocratique

$30 \mathrm{El}$ art. 45 confiere a los legislativos provinciales, «exclusively» la potestad de reformar la Const. de la provincia, en todo lo que no afecte al contenido del art. 41. Pelletier, B., «Les modalités de la modification de la Constitution du Canada» en Revue Juridique Thémis, n. ${ }^{\circ} 33$, p. 11 . Tampoco podrán reformarse unilateralmente aquellos preceptos de la Const. federal que integran la Const. provincia (Constitution Act, 1867). $V$. gr. respecto a Ontario los arts. 63, 65, 69 y 70; respecto a Nueva Escocia y Nuevo Brunswick 64 y 68 o los arts. 63, 65, 68, 71-80, 82-87 que se refieren a Quebec (estos últimos también aluden al legislativo de Ontario).

31 El informe comienza del siguiente modo: «Los habitantes de Alberta siempre han sido líderes y rebeldes, ricos en espíritu y audaces en visión. Alberta misma fue establecida por un grupo de ciudadanos valientes y ambiciosos que, trabajando Juntos, construyeron fuertes lazos para mejorar sus vidas, familias y comunidades. Este mismo espíritu pionero ha llevado, a lo largo de los años, a los habitantes de Alberta a desafiar el status quo». Presidida por Edmonton Rutherford, planteaba una redefinición de las relaciones federal provinciales, especialmente en materia de servicios y tributos (http://www.assembly.ab.ca/lao/library/egovdocs/2004/alii/145363.pdf), En ella se habla de fortalecer las responsabilidades constitucionales provinciales (p. 49), pero no se llega a materializar en un proyecto de reforma para lograr una nueva constitución. En el mismo sentido, Palermo, F., Kössler, C., Comparative federalism: constitutional arrangements and case Law, Bloomsbury, Hart Publishing, 2017, nota. 71.

32 Entre los escasos estudios sobre las constituciones provinciales en Canadá, Quebec ha sido el principal objeto de atención. Cfr. Mchugh, J. T, «The Quebec Constitution,» Quebec Studies, n. ${ }^{\circ}$ 28, 1999, pp. 3-26.

33 En palabras de Alan Tarr, «The province (Quebec) is continuing to explore subnational constitutional possibilities» (p. 769). TARR, A., «Subnational constitutions and minority rights: a perspective on Canadian provincial constitutionalism», Rutgers Law Journal, vol. 40, 2008-2009, pp. 767-792.

34 «L'idée de doter le Québec de sa propre constitution sera presente dans l'histoire nationale du Québec. Du projet de Daniel Johnson à la proposition de Jacques-Yvan Morin (I), des travaux de la Commission Bélanger-Campeau au projet de Loi sur l'avenir du Québec (Projet de loi no 1) (1985-1995) (II), de la Loi sur les droit fondamentaux du Québec (Projet de loi no 99) au rapport du Bloc québécois Pour une Constitution en partage (1996-2001) (III), de la Commission des États généraux sur la langue française à la motion sur la nation québécoise (2001-2006) (IV) et de la proposition de Constitution québécoise de l'Action démocratique du Québec au projet de Constitution du Québec (Projet de loi no 191) (V), l'histoire contemporaine du Québec semble conduire vers l'adoption d'une Constitution du Québec». TurP, D., «Une Constitution du 
du Québec (ADQ) propuso la articulación de una «Charte du Quebec», en cuyo contenido se incluía el derecho a la autodeterminación, registrando en la Asamblea de Quebec el 22 de mayo de ese año de un «Proyecto de Constitución de Quebec» (Proyecto de Ley 191) 35 . Por su parte, el Parti Québecois impulsó la celebración de una pseudo-convención ciudadana, «Estates General», en la que la mayoría de sus delegados apoyaban la articulación de una constitución quebequesa. El triunfo del partido liberal en dichas elecciones desinfló tales pretensiones que, por el momento, no se han recuperado, dejando de lado la presentación en mayo de 2019 de la denominada «Constitución ciudadana de Quebec» ${ }^{36}$, texto elaborado por 42 ciudadanos presididos por Daniel Turp. En las elecciones de 2018, el triunfo de la coalición conservadora Avenir Quebec (CAQ) y el hundimiento del independentismo (el Partido Quebequés solo obtuvo 10 diputados) parecen no albergar un protagonismo a corto plazo para tales proyectos constituyentes.

En consecuencia el espacio que resta para la constitutionalización formal de las provincias canadienses es el habilitado por el artículo 45 de la Constitución de 1982, desde la que también se introducen unos límites a tal potestad, según los cuales no podrá ser objeto de reforma la oficina de la Reina, el Gobernador general o el Gobernador provincial; la representación de la provincia en la Cámara de los comunes con un número de parlamentarios nunca inferior al que le corresponda de senadores; el uso del inglés o del francés; o la composición de la corte suprema de Canadá — para reformar estos aspectos se requeriría el consentimiento unánime de todas las provincias, de conformidad con el art. 41 de la Carta - Es decir, que a través de esas reformas constitucionalizantes no vamos a asistir a la mutación praeter legem de los signos caracterizadores del diseño constitucional canadiense $\mathrm{e}^{37}$.

Por consiguiente, el estudio de las constituciones provinciales canadienses se deriva hacia el terreno académico, la propia narrativa elaborada desde la doctrina constitucional $^{38}$. Esas circunstancias apoyan a comprender que «el constitucionalismo provincial se asienta con dificultad en el subconsciente canadiense. Estas son demasiado opacas, sesgadas e imperfectas para provocar algo de interés y, mucho menos, pasión» ${ }^{39}$.

Québec», Noreau, P. y Rolland, L., Mélanges Andrée Lajoie: Le droit une variable dependante, Montreal, Les editions Thémis, 2008, p. 136.

35 http://www.assnat.qc.ca/fr/travaux-parlementaires/projets-loi/projet-loi-191-38-1.html

36 http://inm.qc.ca/docs/CONSTITUONS/constitution_citoyenne_quebec_INM.pdf

37 Según WisEMAN, «el artículo 45 no permite un profundo cambio constitucional alentado por la introducción de instituciones políticas foráneas e incompatibles con el sistema canadiense». WISEMAN, N., «Clarifying Provincial constitutions», National Journal of Constitutional Law, v. 6, 1996, p. 285.

38 Price, P., «Provincializing Constitutions: History, Narrative, and Disappearance of Canada's Provincial Constitutions», Perspectives on Federalism, vol. 9, issue 3, 2017, p. 22.

39 Wiseman, N., «Clarifying Provincial constitutions», National Journal of Constitutional Law, v. 6, 1996, p. 270. 


\section{II.3. El halo negativo del constitucionalismo estatal federal}

El proceso de federalización no siempre ha ido aparejado de dotar de constituciones a los estados federados. Recuerda Marshfield que cuando Nigeria, a finales de los años setenta de la pasada centuria, afrontó ese proceso y ante la cuestión de si debería permitirse a los estados nigerianos dotarse de su propia constitución la respuesta fue negativa porque ello habría generado un potencial «divisivo» incompatible con la idea federal ${ }^{40}$, e incluso no se dudó en catalogar a las mismas como «enemigas de la unidad del país» ${ }^{41}$. Por ello en este marco comparado no aparecen referencias a ese halo negativo del constitucionalismo estatal, que se complementa con una referencia a estados que, usando el significante de constitución estatal, se alejan de articular normas de esa naturaleza. Es el caso de las entidades federativas mejicanas, conviniendo que en esta Federación «la llamada constitución política de una entidad federativa no es, en sentido estricto, una Constitución, sino una ley reglamentaria de algunos apartados de la Constitución General de la República» ${ }^{42}$, no en vano se las describe como constituciones locales. La Constitución federal impulsó un desacierto normativo al identificar como estados libres y soberanos ${ }^{43}$ a estas entidades territoriales, cuya razón de ser es la autonomía ${ }^{44}$.

\section{EL SURGIMIENTO DE LAS CONSTITUCIONES ESTATALES}

El proceso de creación de un Estado federal determina, de modo indudable, el proceso de gestación de las constituciones de los estados federados. Por ello, las diferencias son notables entre Estados, siendo los datos más relevantes del constitucionalismo estatal norteamericano los siguientes.

La gestación de la federación, su expansión y consolidación ha ido paralela a la vida de las constituciones estatales. Las primeras constituciones estatales fueron adoptadas en 1776 por Delaware, Maryland, New Hampshire, New Jersey, North Carolina, Pennsylvania, South Carolina y Virginia. En el extremo opuesto

40 Marshfield, J.L., «Models of subnational constitutionalism», op. cit.,p. 1152.

41 Elazar, D. J., Exploring federalism, Tuscaloosa, 1987, pp. 166-167.

42 Martí Capitanachi, L. C., «Las Constituciones locales en el sistema federal mexicano ¿son verdaderas constituciones?», Federalismo y Regionalismo. Memoria del VII Congreso Iberoamericano de Derecho Constitucional, México, UNAM, 2002, p. 658.

43 Artículo 40 de la Const. de México. «Es voluntad del pueblo mexicano constituirse en una República representativa, democrática, laica, federal, compuesta de Estados libres y soberanos en todo lo concerniente a su régimen interior; pero unidos en una federación establecida según los principios de esta ley fundamental».

44 Sobre la tensión entre autonomía y soberanía, en Méjico se ha debatido no solo académicamente, sino también jurisprudencialmente. Así, Amparo en Revisión 633/2010, 22 de septiembre de 2010. Segunda Sala. Novena época. Semanario Judicial de la Federación y su Gaceta. Tomo XXXIII. 2011. p. 1471. 
de esa secuencia temporal, Rhode Island revisó su Constitución en 1986, convirtiéndola en la más nueva en su redacción final, siendo en origen las más recientes, Hawaii (1950) y Alaska (1956) ${ }^{45}$.

A la hora de trazar esa evolución de las constituciones estatales norteamericanas, más allá del seguimiento histórico que se ha referido, hemos de prestar atención a las influencias vertidas sobre las mismas. Desde la actuación de principios jurídicos como la cláusula de garantía y de supremacía, las constituciones estatales norteamericanas se han desarrollado a partir de un patrón de comportamiento que es la emulación. Así, la Constitución federal ha sido considerada como un referente a seguir en el caso, esencialmente, de la protección de derechos, pero también en la forma de gobierno, la separación de poderes y la independencia del poder judicial ${ }^{46}$. La interpretación de esta conexión se puede articular a partir de su complementariedad, en una concepción de un derecho federal progresivo e inclusivo. Esa percepción se validaría con una aproximación prospectiva, desde la que las influencias no solo se han referido a la literalidad de la constitución, sino que propuestas de reforma constitucional que no han prosperado a escala federal han tenido cabida en las constituciones estatales. Como por ejemplo en materia de igualdad de trato entre mujeres y hombres ${ }^{47}$.

En la configuración constitucional estatal no solo ha influido la Constitución federal. Esa polución constitucional ha afianzado un federalismo horizontal construido con las aportaciones de otras constituciones estatales. Aquí, la evolución histórica también es decisiva, pudiéndose identificar tres etapas ${ }^{48}$. La primera, referida a la elaboración de las primeras constituciones donde el papel del Congreso Continental ayudaría al intercambio constitucional. La segunda, centrada en el siglo XIX, momento de mayor eclosión constitucional, donde las leyes de habilitación marcaban la necesidad de asegurar el seguimiento de los patrones confeccionados por las constituciones de los estados que ya habían ingresado en la Unión. Finalmente, el siglo xx con el cierre del modelo constitucional llevará

45 TArr, G.A., «Of time, place, and the Alaska Constitution», Alaska Law Review, vol. 35:2, pp. 155 177. Enfatiza la importancia de cuándo y dónde se originó una constitución estatal para comprenderla.

46 Fritz, C., «The American Constitutional Tradition Revisited: Preliminary observation on State Constitution-Making in the Nineteenth-Century war», Rutgers Law Journal, n. ${ }^{\circ} 25,1994$, pp. 945-998.

47 Con el acrónimo ERA's (Equal Rights amendments) se alude a la inclusión en las constituciones estatales de los derechos de interdicción de la discriminación entre hombres y mujeres, a las que se uniría otro tipo de causas como el origen, o la situación física o psíquica. CARP, R.A. (et. al), Judicial process in America, CQ Press, 2016, p. 391. V.gr. Art. I §18, de la Const. de Illinois («no discrimination on the basis of sex»). En 1974 se reformó el art. I $\$ 20$ de la Const. de Connecticut, para introducir esa prohibición de discriminación por razón de género, que se ampliaría en 1984 a la discapacidad física o mental. A finales de los 90’s Constituciones como la de Florida o Iowa incorporarían ese derecho a la igualdad. Art. I, § 2, Const. de Florida («female and male alike, are equal before the law and have inalienable rights»); art. I, $\S 1$, de la Const. de Iowa; art. II, § 29, de la Const. de Colorado.

48 Se han articulado a partir del análisis de Tarr sobre las influencias interestatales sobre los procesos del cambio constitucional en los estados. TARR, A., Understanding State Constitutions, Princeton, Princeton University Press, 1998, pp. 50-55. 
aparejada una profesionalización del quehacer constituyente. El prototipo no serán las constituciones del entorno, sino aquellas que se perfilen como más solventes y acordes con las necesidades de un derecho en constante evolución que afronta los retos del siglo XXI ${ }^{49}$.

La popularización de las constituciones se afianza de la mano de una hipertrofia reformista que se cuela en la definición de la cultura política de los estados y que se articula como un reducto de salida a la gestión política ordinaria que convierte la tarea de enmendar la constitución en algo más sencillo que tramitar una ley consecuencia de la no aplicación a la misma del veto del ejecutivo. En ese terreno pro-reformista de las constituciones estatales se advierte, al igual que en la configuración del common law, la aparición de una paralela llamada a la necesidad de armonizar contenidos, esto es, de los riesgos de la dispersión y atomización normativa. En 1919 se articula la denominada «constitución estatal modelo» (vid. supra), diseñada desde la Liga Municipal Nacional que abogaba por introducir la iniciativa popular constitucional y estatal; por potenciar la autonomía local, así como un modelo pseudo-directorial en el que, de la mano de un Consejo legislativo, un gobernador que tendría que ser parlamentario, junto a líderes del poder legislativo controlarían las actuaciones del poder legislativo. En esa lucha por el protagonismo constitucional estatal hay dos vectores que confluyen. En clave económica, las constituciones afianzan su posicionamiento desde el intento de control de los grandes intereses económicos, a la par que se incorpora una dimensión social, avanzando los primeros pasos para consolidar un ejercicio sostenible de las actividades económicas, así como a habilitar un cauce al control ciudadano de la presión fiscal que se le va a aplicar (v. gr. La proposición 13$)^{50}$.

49 Una explicación de este proceso de gestación constitucional más exhaustivo y periodificado es el que articula KINCAID, señalando seis etapas o eras. La primera durante los años 1776-88, en la que 12 estados diseñaron su primera constitución; una segunda, 1789-1865, de expansión de la democracia, en la que 22 estados ingresaron en la Unión con nuevas constituciones y 42 las revisaron; una tercera, 1860-1899, era de la inmigración urbana-industrial. Esta era está marcada por un cambio extensivo en el sur, en la que abandonando la exigencia federal retornaron a constituciones supremacistas; cuarta, 1900-1945, era de las reacción progresista, eficiencia profesional y eficacia pública, en la que aflora el auge de la democracia directa; una quinta, 1945-1977, era de la reforma profesional post-bélica, modernización de los estados y complemento estatal del poder federal. Se apuesta por la profesionalización constitucional, procediendo a la supresión de las convenciones constitucionales por comisiones de expertos; finalmente, una sexta era actual que se describe como de revueltas públicas y moderación en la modernización, en la que destaca el impulso ciudadano a las reformas constitucionales tendentes a la limitación de gasto y de la potestad impositiva estatal (TEL's, Tax and expenditure limits). KINCAID, J., «Early State history and constitutions», HaIdER-MARKeL, D.P, The Oxford Handbook of State and local government, London, Oxford University Press, 2014, pp. 244-262.

50 La Proposición 13, aprobada en California en 1978, fue una iniciativa ciudadana (Jarvis-Gann) de la que resultó la modificación de la Const. de California (art. XIII) con la que se insertó una limitación al valor de la propiedad con finalidades tributarias desde su valor de mercado al valor de su adquisición. Limitó los incrementos impositivos al $2 \%$ por año, a menos que se vendiera la propiedad, y requería una mayoría de $2 / 3$ para aprobar leyes estatales que subieran otros impuestos. Muchos observadores argumentan que la Proposición 13 desencadenó una revuelta fiscal a nivel nacional (La proposición 2 de Massachussets) y allanó el camino para que Ronald Reagan, Gobernador de California entre 1967 y 1975, llegase a la Casa Blanca. Citrin, J., «Proposition 13 and the transformation of California Government», California Journal of Politics and Policy, 
Un segundo pilar en la ampliación del protagonismo de las constituciones estatales, en particular de su carta de derechos se produce como consecuencia de la mano del denominado «nuevo federalismo judicial $»^{51}$, que a lo largo de los años 70 se consolidó como respuesta a una tensión constituciones vs. poder judicial. Si los tribunales estatales habían anulado disposiciones constitucionales de los Estados ${ }^{52}$, el nuevo federalismo judicial parece compensar a estas normas fundamentales estatales en las que se hallan unas garantías a los derechos de los ciudadanos que no existen en la Constitución de los Estados Unidos.

\section{CARÁCTER NORMATIVO O PROGRAMÁTICO DE LAS CONSTITUCIONES ESTATALES: ¿ESTAMOS ANTE AUTÉNTICAS CONSTITUCIONES?}

Una cuestión clave para entender la posición jurídica de las constituciones estatales es analizar su naturaleza. Esta cuestión se eleva desde el avance de sus contenidos que se vinculan a amplitud, minuciosidad y coyunturalidad. A priori, ya apercibimos una contradicción entre la dimensión general de la norma, ponderada en una norma constitucional, y la minuciosidad de las prescripciones de las constituciones estatales.

Ahí surge la esencia del planteamiento sobre si estamos ante una constitución normativa o su naturaleza es, en todo o en parte, la derivada de un contenido material «programático», en la medida en que las constituciones recogerían

Vol. 1 [2009], Iss. 1, Art. 16, pp. 1-9. Los albores del siglo xxi, afianzaron esta dimensión revolucionaria de las constituciones estatales con el movimiento TEL's (Tax and expenditure limits). En 2003, la Const. de Texas aprobó una enmienda que congelaba los impuestos a la propiedad a personas mayores y discapacitados. (Art. VIII, secc 1-b). Esta tendencia se extendería a Arkansas, Indiana, Florida, New Mexico o Tennessee identificando colectivos vulnerables como viudas/os, veteranos con discapacidad o mayores de 65 a los que se aplicarán esas exenciones fiscales. Una variante de este activismo fiscal de las constituciones fue el incorporado por Michigan, al aprobar la enmienda Headlee, que introduce una autolimitación a la recaudación de impuestos sobre la renta de las personas al 9,49 de los ingresos estatales por ese concepto. Si los ingresos excediesen en un $1 \%$ esa cantidad retornarían a los contribuyentes, si fuesen menores pasarían a integrarse en un fondo que sustenta una base para la estabilización presupuestaria («rainy day»). Washington, Missouri y Florida actuarían en la misma línea. KINCAID, J., «Early State history and constitutions», op. cit., pp. 256-257.

51 Alude al creciente sustento de la jurisprudencia estatal en las declaraciones de derechos de las constituciones estatales a los efectos de garantizar derechos no contemplados en la Const. de los Estados Unidos. BRENNAN, W.J., «State constitutions and the protection of individual rights», Harvard Law Review, n. ${ }^{\circ}$ 98, 1977, p. 495 o TARr, A., «New judicial federalism in perspective», Notre Dame Law Review, Vol. 72, Issue 4, 1997, p. 1097. La literatura que documenta el nuevo federalismo judicial es muy amplia. Cabría destacar las siguientes publicaciones que lo han abordado de forma monográfica: «Developments in the Law: The Interpretation of State Constitutional Rights», Vol. 95, n. 6 Harvard Law Review, abril 1982, pp. 1324-1502; New developments in State Constitutional Law, monográfico de Publius. The Journal of Federalism, Vol. 17., n. ${ }^{\circ}$ 1, Winter 1987, en particular el artículo de TARr, A. y PORTER, C., «State Constitutionalism and State Constitutional Law», pp. 1-12 o el libro editado por Friedelbaum, S. H., Human rights in the states, Santa Barbara, Praeger, 1988.

52 El art. I, secc. 27 de la Const. de California, derogado por People vs. Anderson, 493 p. 2d 880 (1972). Lo mismo con el art. I, secc. 12 de la Const. de Florida o el art. 26 de la Const. de Massachusetts. 
indicaciones detalladas a los poderes públicos, particularmente al legislativo, pero también al ejecutivo e, incluso, al judicial. Primero, cuando pensamos en la entidad jurídica de las constituciones estatales la dialéctica se traba entre una naturaleza obligatoria («mandatory») versus programática, facultativa o permisiva $(« \text { directory» })^{53}$.

En segundo lugar, desde la consideración de la minuciosidad de los detalles que se introducen en el contenido constitucional, se apuntaría hacia una infraconstitucionalidad material ${ }^{54}$, propia de leyes ordinarias e, incluso, de normas infralegales de carácter reglamentario.

Una respuesta basada en la interpretación literal de las constituciones estatales tampoco ayuda demasiado en este debate. Así, el art. I, secc. 23 de la Constitución de Carolina del Sur (1895) establece que «las disposiciones de la Constitución serán adoptadas, consideradas e interpretadas como disposiciones obligatorias o prohibiciones, y no meramente con un carácter directivo, excepto allí donde se señale de modo expreso esa forma directiva o permisiva» ${ }^{55}$.

Las constituciones estatales son normativas en su integridad. El matiz se halla en el terreno de la aplicación, pero no en el de la naturaleza. «La Constitución del Estado fue adoptada por el pueblo del Estado como la norma fundamental del Estado. Esta ley fundamental fue concebida por el pueblo como restrictiva respecto a los poderes de los distintos departamentos gubernamentales creados por ella. Cada uno de sus mandatos se concibió como un parámetro de autoridad para todas las personas que ostentan un cargo oficial, para todos los departamentos gubernamentales y para todos los ciudadanos» ${ }^{56}$. Por consiguiente, esa naturaleza normativa se justifica y se sustenta en la propia legitimidad de la Constitución que se blinda con esa legalidad suprema a nivel estatal.

El estudio de las constituciones estatales en el contexto de las fuentes del derecho en los Estados Unidos supone el desvanecimiento de, al menos, dos mitos. Por un lado, el sistema jurídico no es exclusivamente casuístico y jurisprudencial ${ }^{57}$. Por otro, las constituciones estatales no son fruto únicamente de la actividad legisladora de los estados federados ${ }^{58}$. La constitución estatal es la norma

53 Williams, R.F., State Constitutional Law. Cases and materials. Lexis Nexis, Newark, 2006 (4. ${ }^{a}$ edic.). p. 421 .

54 Article x b Marine Resources Protection Act of 1990 [section 1 - sec. 16] (Article 10B added Nov. 6, 1990, by Prop. 132. Initiative measure.) Ley de protección de los recursos marinos, 1990. Const. de California.

55 Esta disposición aparecía en la redacción original de 1895, habiéndose cambiado a raíz de la reforma de 1971 únicamente su numeración desde la originaria secc. 29.

56 Arnett v. Sullivan, 132 S.W.2d 76 (Ky. Ct. App. 1939) Court of Appeals of Kentucky (pre-1976), 29 de septiembre de 1939.

57 Furnish, D. B., «Las fuentes del derecho en Estados Unidos. La muerte del derecho consuetudinario, las fuentes escritas en la edad del derecho positivo y el papel y efecto de los Restatements of the Law», LI Revista de la Facultad de Derecho de la UNAM, Universidad Nacional Autónoma de México, 2001, p. 77.

58 A través de las leyes de habilitación el Congreso autoriza a los estados que solicitan formar parte de la Unión a solicitar el reconocimiento de ese status desde la constatación de disponer de una constitución sobre 
suprema de cada estado federado, «Supreme Law of the State» ${ }^{59}$. Las consecuencias derivadas de esa declaración de supremacía son la nulidad de las leyes que entren en contradicción con la misma y el mandato de su desarrollo a los poderes constituidos, en particular al poder legislativo ${ }^{60}$. Más dudas nos suscita la inserción en alguna Constitución estatal de artículos donde se introduce de modo expreso el requisito de que sea preciso el consentimiento de los Estados Unidos, así como el del Estado, para revocar o alterar determinadas partes de su Constitución. Es el caso del art. III de la Constitución de Utah, donde determinadas materias como el matrimonio polígamo, la liberación de la educación de un control sectario, la asunción de las deudas contraídas por el propio estado para su pago por él mismo o la renuncia a reclamar la propiedad de terrenos de dominio público, necesitarán, en virtud de una ordenanza introducida en la Constitución «el consentimiento de los Estados Unidos» y del pueblo de este Estado.

La Constitución federal imprime una serie de exigencias a esa integración, la cláusula de garantía y la cláusula de supremacía. La cláusula de garantía (art. IV, secc. $4 .^{\circ}$ de la Constitución de 1787) impone una forma republicana de gobierno a cada estado de la unión. En la acepción constitucional de forma republicana se entiende como sinónima de democrática. Esta garantía se ha interpretado de un modo aparentemente contradictorio. Primero, en un sentido positivo como fundamento de la supervisión constitucional del desarrollo de la Unión. Segundo, en un sentido negativo, en cuanto límite a ulteriores intromisiones que pudieran producirse desde la Unión hacia los estados, salvaguardados precisamente en ese carácter democrático de su estructura de gobierno. La interpretación jurisprudencial ha entendido esta garantía como un elemento político de la Unión y, por consiguiente, exento de supervisión judicial. Una de las escasas aplicaciones de esta garantía fue en la denominada rebelión Dorr, cuando el gobierno federal tuvo que dirimir cuál era el verdadero gobierno de Rhode Island en 1841-42 ${ }^{61}$. En el pro-

la cual el Congreso podría imponer condiciones materiales para su elaboración por los constituyentes estatales, que han de ser asumidas por sus constituyentes como requisito para poder recibir el voto favorable del legislativo federal. Este requisito procesal, que sería la codecisión federal-federado en la configuración de las constituciones estatales, agota su eficacia en el propio acto de admisión y concesión del status de estatidad. Tras su admisión los estados ostentaban con plenitud la totalidad de los poderes de «soberanía y jurisdicción que pertenecían a los estados originales».Coyle vs. Smith 1911, 221 US 5591911.

59 v. gr. art. X, secc. 6 Const. de Maine

60 Así, La Const. de Iowa, art. XII, secc. 1. «This Constitution shall be the supreme law of the state, and any law inconsistent therewith, shall be void. The general assembly shall pass all laws necessary to carry this Constitution into effect».

61 El contexto es un marco constitucional colonial que seguía utilizando la Carta constitucional de 1663 como constitución, enfrentando una sociedad elitista y rural a una sociedad urbana de clase media que rechazaba la vinculación del derecho al voto a la propiedad. Durante seis semanas, en 1842, hubo dos gobiernos rivales. Tras dos convenciones constituyentes paralelas, se aprobaron dos constituciones, la Constitución del Pueblo, sustentada por Dorr y la Constitución de los Hombres Libres. Hubo, correlativamente, dos gobiernos, el de Dorr y el del Gobernador Samuel Ward King. En la sentencia Luther v. Borden, 48 U.S. (7 How.) 1 (1849) se sostuvo el derecho constitucional a cambiar de gobierno, pero la naturaleza política de tal acto, no jurídica, impedía al tribunal hacer mayores consideraciones al respecto, por lo que el apoyo moral a 
ceso post-guerra civil de reconstrucción el recurso a esta cláusula de garantía fue un deseo que se topó de lleno con la autonomía constitucional de los estados soberanos que se esgrimía desde el sur.

La cláusula de supremacía (art. VI, secc. 2) viene a confirmar que dentro de una esfera de competencias el derecho federal es superior al derecho estatal y que los actos jurídicos federales — sean disposiciones, leyes o reglamentos administrativos - adquieren precedencia sobre las disposiciones constitucionales en caso de conflicto. Esta cláusula llevaría a declarar la inconsistencia de la Constitución de Missouri con la Constitución federal al incluir un juramento de lealtad que excluía a la Constitución federal ${ }^{62}$ y, por otro lado, la inserción en constituciones, como la de West Virginia, art. 1, del reconocimiento a la supremacía de la Constitución federal de modo expreso ${ }^{63}$.

\section{ESTRUCTURA Y CONTENIDO DE LAS CONSTITUCIONES ESTATALES}

La estructura de las constituciones sigue un esquema tradicional de división en una parte dogmática y parte orgánica. Es habitual la inserción de un preámbulo, iniciado de modo retórico con la expresión «we the people», agregado el respectivo estado y unas referencias a $\operatorname{Dios}^{64}$, en el que se ordena la redacción de la constitución, así como algún artículo de cabecera en el que suele referirse la delimitación del territorio del estado, a veces con un grado de detalle que resulta pormenorizado en exceso, v. gr. Arizona ${ }^{65}$, que se acompaña con una referencia a la posibilidad de modificación de dichas fronteras estatales para lo que se requiere el acuerdo con el estado afectado y la formalización del mismo mediante la aprobación del Legislativo. La eficacia jurídica de los preámbulos de las constituciones

Dorr se tradujo en una inacción real. Conley, P, «Popular sovereingty or public anarchy? America debates the Dorr rebellion», Rhode Island History, vol. 60, n. 3, 2002, pp. 71-91.

62 Cummings vs. Missouri 71 U.S. 277 (1867)

63 Art. 1, secc. 1 «The State of West Virginia shall be and remain one of the United States of America. The Constitution of the United States, and the laws and treaties made in pursuance thereof, shall be the supreme law of the land».

$64 V . g r$. «We the people of the State of New York, grateful to Almighty God for our Freedom, in order to secure its blessings, do establish this constitution». Una excepción por su redacción más detallada es el Preámbulo de la Const. de Lousiana: «Nosotros, el pueblo de Louisiana, agradecemos a Dios todopoderoso las libertades civiles, políticas, económicas y religiosas que disfrutamos, y deseamos proteger los derechos individuales a la vida, la libertad y la propiedad (...); y asegurar las bendiciones de la libertad y justicia a nosotros mismos y a la posteridad, ordenamos y establecemos esta constitución».

65 Art. 1, secc. 1 de la Const. de Arizona: «Los límites del Estado de Arizona serán los siguientes, a saber: Comenzando en un punto en el Río Colorado veinte millas inglesas por debajo del cruce de los ríos Gila y Colorado, según lo establecido por el Tratado de Gadsden entre los Estados Unidos y México, estando en la latitud treinta y dos grados, veintinueve minutos, cuarenta y cuatro y cuarenta y cinco centésimas de segundos al norte y la longitud ciento catorce grados, cuarenta y ocho minutos, cuarenta y cuatro y cincuenta y tres uno-centésimas de segundos al oeste de Greenwich; (...)». 
estatales es menor, si bien se hace referencia a los mismos como apoyatura en alguna sentencia. Así, referido al concepto de religión ${ }^{66}$ que se usa, o en otras referencias jurisprudenciales que tienen como eje a la familia ${ }^{67}$.

Uno de las principales características, y no precisamente positiva, de las constituciones estatales es la dispersión de sus contenidos y el grado de detalle y minuciosidad con que los han reflejado. En ocasiones han sido un reflejo de la pura vida de los estados, como la preocupación de la construcción de pistas de esquí en las colinas de las montañas de Belleayre en los condados de Ulster y Delaware, con unas medidas definidas (Constitución de Nueva York, art. XIV, secc. 1), contextualizadas dentro de la preservación de reservas forestales y de las excepciones a la misma, a las que se uniría la construcción de carreteras estatales eliminando los peligros de curvas, el sistema de carreteras públicas y su modo de financiación (art. XIV de la Constitución de Minnesota) o la venta de alcohol en vasos individuales como uno de los derechos integrados en la carta de derechos de la Constitución de Oregón (art. I secc. 39), mismo texto que dedica su articulado a regular la Universidad de Oregón de Salud y Ciencias (art. XI-L). Un análisis de las principales líneas directrices del texto de las constituciones estatales nos lleva a las siguientes apreciaciones.

\section{V.1. Principios estructurales de las constituciones estatales}

Las constituciones estatales ofrecen una impronta uniforme desde una aproximación estructural sobre esa base formal de distinción entre parte dogmática y orgánica, que se aproxima al constitucionalismo europeo, pero que se aleja del federal norteamericano por su propia evolución histórica que ubica el catálogo de derechos en la parte final de la Constitución de la mano de las enmiendas.

Si hubiéramos de identificar una fórmula política común a las constituciones estatales, principios constitucionales, esta se referiría a la división tripartita de poderes, a la forma de gobierno, al sistema electoral, a la garantía de un catálogo de derechos y a un sistema de reforma flexible en sus resultados, pero

66 Roberts v. Ravenwood Church of Wicca, 249 Ga. 348 (1982). Se trataba de una demanda en apelación de una iglesia denominada Iglesia Ravenwood de Wicca, que reclamaba la exención fiscal por un edificio de su titularidad. La singularidad de este movimiento se vincula a la demonología. En su argumentación el tribunal, apela al preámbulo para desmontar la calificación de religión al culto profesado por este movimiento. Así, «la opinión de la mayoría afirma que la iglesia wicca no cree en el diablo, no entendiendo que se ajuste al concepto tradicional de una religión tal como se incluye en el preámbulo de nuestra Constitución del Estado y como se expresa en el Compromiso de lealtad a la bandera de los Estados Unidos. Esta nación fue fundada «bajo Dios», no el «círculo kármico».

67 Clabough v. Rachwal, 335 S.E.2d 648 (Ga. Ct. App. 1985) Court of Appeals of Georgia. «La preservación de la unidad familiar es de la mayor importancia en este estado que recientemente se le ha dado estatura en nuestra constitución estatal: «Para . promover el interés y la felicidad del ciudadano y de la familia, nosotros, las personas de Georgia . ordene y establezca esta Constitución «. 
complejo procesalmente $^{68}$. La práctica totalidad de las constituciones estatales reconocen la separación de poderes, legislativo, ejecutivo y judicial, orgánicamente articulados y con la prohibición expresa de participar en otras funciones que aquellas propias del órgano específico, con la inquietante salvedad de la Constitución de Wyoming que expresamente inserta la excepción a esta tajante separación de poderes «en aquello que esta constitución expresamente dirija o permita» (art. II).

En el caso norteamericano las cincuenta constituciones no han optado por una forma parlamentaria de gobierno, han abogado por el protagonismo de los ciudadanos en la monitorización de las actuaciones políticas buscando enfatizar quién ostenta la legitimidad de sus procesos y han utilizado su parte dogmática para imprimir la cultura política particular de cada estado. Por ello, la concepción de los derechos difiere entre las propias constituciones e, incluso, respecto a la federal. Con todo, el común denominador a todas ellas hace alusión a las importantes funciones que a las constituciones estatales se atribuyen: «1. Sobre todo, marcos de gobierno para los sistemas políticos que son, en la mayoría de casos, más y menor desarrollados que los de las demás naciones del mundo; 2. Expresiones políticas prácticas de teoría política y de los fines del gobierno; 3. Reflexiones de las concepciones públicas de los roles propios del gobierno y de la gestión pública» ${ }^{69}$.

\section{V.2. Parte dogmática}

El concepto de federalismo se ha reforzado a partir de la consolidación de la parte dogmática de las constituciones estatales ${ }^{70}$. La importancia y la necesidad de

68 Lutz cataloga como principio del diseño constitucional estatal el proceso de reforma constitucional. Lutz, D. S., «Toward a theory of constitutional amendment», The American Political Sciencie Review, vol. 88, n. ${ }^{\circ} 2$, jun. 1994 , p. 356.

69 Elazar, D.J., «The principles and traditions underlying state constitutions», Publius: the Journal of Federalism, 12, Winter 1982, p. 12.

70 La trazabilidad de los catálogos de derechos en Estados Unidos puede compactarse en el siguiente iter. Antes de que se incluyera la XIV enmienda en la Constitución, año 1868, el Tribunal Supremo sostenía que la Bill of Rights no restringía a los estados, sino solo a la acción federal. En 1897 se quebraría esa tendencia en lo que respecta a la expansión a los estados de utilizar la propiedad privada para usos públicos sin una justa compensación -Chicago B. E Q.R.R. v. Chicago, 166 U.S. 226, 241 (1897) — Esa evolución se afianzó en 1925, cuando se contempló la aplicación a los estados de la primera enmienda, consolidándose en 1961 — Mapp v. Obio, 367 U.S. 643 (1961)—. Entre 1962 y 1969 se imprimió un profundo impacto en vida americana como consecuencia de la expansión a los estados de la Carta de derechos federal. La tendencia sufrió un profundo revulsivo en los años 70, cuando los tribunales estatales consolidaron un marco jurídico que dispensaba mayor protección a los ciudadanos a partir de los derechos integrados en las constituciones estatales (nuevo federalismo judicial), lo que supondría «un importante y altamente significativo desarrollo de nuestra jurisprudencia constitucional y para nuestro concepto de federalismo». BRENNAN, W.J., "State constitutions and the protection of individual rights», op. cit., p. 495. 
la inclusión de los catálogos de derechos en estas constituciones ha evolucionado de modo paralelo a la creciente complejidad de la sociedad, la política y el desarrollo económico. En ese sentido, las constituciones subnacionales han incorporado derechos clásicos, pero a la par se han convertido en repositorios privilegiados de nuevos, «modernos», derechos (modern state constitutional rights) ${ }^{71}$. El giro copernicano que supuso el «nuevo federalismo judicial», tal y como se describe por el Juez Brennan ${ }^{72}$, referido a la interpretación por parte de los tribunales estatales de los derechos recogidos en dichas constituciones, intensificando con ello la protección jurídica de los ciudadanos respecto a los derechos contemplados en la Constitución federal, ha catapultado, redescubierto ${ }^{73}$, estos catálogos de derechos y las constituciones en las que se integran a una posición relevante en el proceso de construcción federal.

Una triple aproximación nos lleva a contemplar esta parte dogmática de las constituciones estatales desde un plano formal, otro material y, finalmente, desde una visión prospectiva de los mismos.

Formalmente, es frecuente que los derechos constitucionales estatales se integren en el primer artículo de una constitución estatal ${ }^{74}$, si bien pueden aparecer dispersos a lo largo de todo el texto constitucional, especialmente derechos vinculados a la educación ${ }^{75}$, el medioambiente ${ }^{76} \mathrm{o}$ al procedimiento legislativo ${ }^{77}$. La articulación de los diferentes derechos no aparece estructurada de modo jerárquico, ni en atención a sus garantías, ni tampoco temáticamente.

Materialmente, podríamos articular diferentes clasificaciones de los derechos estatales. En primer lugar, la que distinguiría, grosso modo, entre los derechos idénticos o similares a los constitucionalizados a nivel estatal y aquellos otros que suponen un espacio de innovación en el ámbito de los derechos y libertades. En

71 Williams, R., «Rights», Tarr, A., y Williams, R., State Constitutions for the Twenty-first Century. The agenda of State Constitutional Reform. Albany, State University of New York Press, 2006, p. 7.

72 Brennan, W., «The Bill of rights and the States: the revival of state constitutions as guardians of individual rights», 61 New York University Law Review 535 (1986), p. 535.

73 Williams, R. F., The law of the american state constitutions, op. cit, p. 113. En este trabajo se analiza con minuciosidad la evolución del Nuevo federalismo judicial, desde una primera etapa, marcada por el caso People vs. Anderson 493 P. 2d 880 (Cal 1972), en el que el Tribunal Supremo de California declaró inconstitucional la pena de muerte a partir de la interdicción de la constitución californiana de los castigos crueles e inusuales, pasando por, a comienzos de los 80’s, de una reacción contraria al mismo rechazando que las decisiones de los tribunales estatales fueran más allá de los estándares nacionales, llegando a reformar las constituciones estatales a los efectos de constreñir tales pronunciamientos a los parámetros federales. Esa etapa se superó a finales de los 90's donde se advierte paralelamente la consolidación del nuevo federalismo judicial y la constante dificultad de los juristas de argumentar sus pretensiones de modo solvente únicamente en el derecho constitucional estatal. La cuarta etapa, en ciernes, se vertebraría acerca de la necesidad de un diálogo entre jurisdicciones, estatal-federal. Pp. 113-134.

74 Art. 1, Const. de Illinois, con la expresión Bill of Rights. O con el nombre de Declaración de Derechos, art. I, de la Const. de Lousiana.

75 Art. 8, $\S \S 201-213$, Const. de Mississippi.

76 Art. 11, Secc. 2, Const. de Illionis.

77 Art. 3, Const. de Texas. 
este terreno podemos sostener esa diferencia cualitativa y cuantitativamente. Frente a la convicción generalizada de esa mayor protección ${ }^{78}$, las constituciones federales también han introducido restricciones de derechos con respecto a lo regulado en la Constitución federal, $v$. gr. Constitución de California en materia de evidencia criminal en los procesos penales (art. I secc. 28 1), aunque donde hay un menor nivel de protección, «es preciso respetar los estándares mínimos federales ${ }^{79}$. En segundo lugar, nos podríamos aproximar a ellos desde el criterio generacional $^{80}$, identificando derechos civiles y políticos; sociales, económicos y culturales y unos de tercera generación vinculados a la justicia, la paz y la solidaridad. En la configuración concreta de cada derecho podemos advertir su formulación ora como derechos tanto positivos ${ }^{81}$, trasladándose a mandatos a la acción gubernamental, —una disposición constitucional destinando fondos y ordenando actuaciones para la protección de la salud_- ora como negativos ${ }^{82}$ - las restricciones constitucionales a los poderes públicos para respetar la libertad religiosa, limitando a los poderes públicos que interfieran en el desarrollo de dichos derechos. En esa aproximación material también hay que hacer una referencia a la eficacia de los derechos constitucionales estatales. A diferencia de los derechos federales, los derechos constitucionales estatales contienen restricciones a las actuaciones de los particulares ${ }^{83}$, no solo de las instituciones. Los tribunales ${ }^{84}$ han

78 Tarr, G.A., «Subnational constitutions and minority rights», Tarr, A., Williams, R.F., y MARKo, J., Federalism, subnational constitucions and minority rights, op. cit., p. 94.

79 Williams, R., «Rights», op. cit., p. 10.

80 VASAK, K., «La larga lucha por los derechos humanos», El correo de la UNESCO, noviembre 1977 , pp. 29-32.

81 Art. IX, §1, Const. de Idaho, respecto al derecho de educación, establece el deber del legislativo de Idaho de establecer un sistema uniforme y libre de escuelas, a partir del prius que la estabilidad de una forma republicana de gobierno (entiéndase democrática) depende principalmente de la inteligencia de la gente. El colectivo de veteranos ha sido objeto de la consignación de derechos y acciones positivas desde las constituciones. Así, art. V $§ 6$ y art. VII $\S 18$ de la Const. de Nueva York. Zackin argumenta que, frente a la tradición liberal que impregna el constitucionalismo norteamericano, se ha abierto una brecha en pro de los derechos positivos, especialmente en ámbitos como la educación, la protección de los trabajadores y el medioambiente. ZACKIN, E., Looking for rights in all the wrong places. Why State Constitutions contain America's positive rights. Princeton, Princeton University Press, 2013, p. 106.

82 El art. II, §30b de la Const. de Colorado proclamaba un derecho descrito como «ningún status protegido basado en la orientación homosexual, lesbiana o bisexual», impidiendo cualquier actuación de los poderes públicos estatales y locales que atienda una reclamación o demande un status de protección desde su condición de homosexual o bisexual. Aprobada en 1992, fue anulada judicialmente en 1996. CURRIE, P., «Positive and Negative Constitutional Rights», University of Chicago Law Review 53 (1986), p. 864.

83 Art. I, secc. 12, Const. de Louisiana (interdicción de la discriminación en el acceso a un alojamiento). Art. I, secc. 19, Const. de New Jersey (el derecho de las personas que trabajan en el sector privado para organizarse y reclamar colectivamente).

$84 \mathrm{La}$ interpretación judicial de los derechos se ha topado con dos líneas de resistencia. Por un lado, la tensión entre tribunales estatales y tribunal Supremo. Se advierte un freno a la interpretación de los derechos por los tribunales estatales, a partir de una aplicación preferente de la interpretación federal de los mismos, potenciada por las reformas de las constituciones estatales. V. gr. Art. I, secc. 12, de la Const. de Florida, reformada en 1982. Esto abre el segundo frente, la pugna entre la soberanía legislativa de los parlamentos y la soberanía jurídica de los tribunales que ha hallado en estos derechos un marco muy ilustrativo. Las 
ostentado el monopolio en la aplicación y supervisión de la eficacia de dichos derechos, lo que no obsta que desde los mismos se articulen obligaciones para los restantes poderes públicos, estatales y locales ${ }^{85}$.

Una glosa ilustrativa de los mismos, siguiendo ese patrón generacional, se presenta del siguiente modo. Como punto de partida destaca la regulación de la dignidad de la persona, como fundamento de los derechos ( $V . g r$. Constitución de Louisiana, art. I, secc. 3), para ahondar en las garantías de un proceso debido ${ }^{86}$ y el derecho a un juicio justo ${ }^{87}$, respecto al cual se detallan los derechos del acusado $^{88}$, los derechos de la víctima ${ }^{89}$ —ejemplo prototípico de federalismo horizontal y

decisiones constitucionales estatales aplicadas por los tribunales han anulado lo acordado por los legislativos, que a su vez también pueden proceder a revocar los pronunciamientos judiciales a partir de su potestad de reformar las constituciones. Un ejemplo paradigmático de este «juego de pelota» entre poder estatal constituyente derivado, poderes constituidos y tribunales se ilustra con la denominada Proposición 8, que en California en 2008 eliminaría el derecho a contraer matrimonio entre personas del mismo sexo. El punto de partida es la proposición 22, que en marzo de 2000 agregaría el apartado 308.5 al código de familia californiano estableciendo que «solo el matrimonio entre un hombre y una mujer es válido y reconocido en California». Un segundo momento se sitúa en mayo de 2008, cuando el Tribunal Supremo de California dictamina que esa restricción vulnera la Constitución estatal (In re Marriage Cases, 183 P.3d 384 (Cal. 2008). El tercer paso es la reacción a dicho pronunciamiento de la mano de una iniciativa popular de reforma constitucional, Proposición 8, Eliminates Right of Same-Sex Couples to Marry. Initiative Constitutional Amendment, que se aprobaría por un $52 \%$ de los votos en un referéndum celebrado el 4 de noviembre de 2008. Se introduciría en el art. I Sec. 7.5, de la Const. de California: «Only marriage between a man and a woman is valid or recognized in California». Esa proposición fue objeto de cuestionamiento judicial (se reclamaba que era una revisión constitucional, no una reforma por afectar a derechos fundamentales y su aplicación retroactiva), siendo la respuesta del Tribunal Supremo de California que la enmienda era válida y que su aplicación tenía que ser prospectiva, nunca retroactiva (Strauss v. Horton, 207 P.3d 48 (Ca. 2009). A partir de ahí se inicia una andadura procesal ante los tribunales estatales y federales que se culminará en 2015 con la prohibición del veto a los matrimonios entre personas del mismo sexo Obergefell v. Hodges, 135 S.Ct. 2584 (U.S. 2015) - 2010, United States District Court for the Northern District of California - Perry v. Schwarzenegger, declarando la prohibición inconstitucional por el Juez Walker; noviembre 2011, el Tribunal Supremo de California habilita el recurso de los defensores de la Proposición 8 ante el Ninth Circuit, Perry v. Brown; febrero 2012, se confirma la inconstitucionalidad de la Proposición por dicho Noveno Circuito; se apela la revisión ante el Tribunal Supremo de los Estados Unidos, donde en 2013 se reafirma la inconstitucionalidad de la DOMA, Defense of marriage Act, aprobrada bajo el mandato de Bill Clinton en 1996, prohibiendo el matrimonio entre personal del mismo sexo, Hollingsworth v. Perry 570 U.S. (2013)—. Sмiтh, A., Same-Sex Marriages: Legal Issues, Congressional Research Service 7-5700, p. 18.

85 El novedoso derecho a la «preservación de la libertad de elegir un sistema de cuidado de la salud y sus coberturas», introducido en 2011, en el art. I, \$ 21 A de la Const. de Ohio, tiene como destinatarios a los poderes federal, estatal o local.

86 Art. II, § 25, Const. de Colorado.

87 Art. I, secc. 7 (a), Const. de California.

88 Art. XII, Const. de Massachussets.

89 Art. I, par. 2 Const. de New Jersey. Respecto a la «ola nacional de proteger los derechos de las víctimas», véase WEGLYN, R.E., «New Jersey constitutional amendments for victims'rights: symbolic victory'», 25 Rutgers L.J. 183 (1993-1994), p. 183. El origen de esta corriente reformadora se sitúa en el año 2009 en el que se funda Marsy's Law for all, que se insertaría en diversas constituciones, ej. Oklahoma, donde se aprobaría popularmente en noviembre de 2018 (State Question 794). Su promotor fue Henry Nicholas, cuya hermana, Marsalee (Marsy) fue asesinada por su exnovio en 1983. Poco tiempo después, él y su madre se encontraron con el asesino que había sido puesto en libertad sin haberles trasladado información al respecto. Desde ese momento iniciaron un proceso para blindar constitucionalmente el derecho de las víctimas, 
diálogo entre constituciones estatales-, el inicio del procedimiento, habeas corpus $^{90}$, los derechos a las pruebas y exámenes preliminares y otros elementos procesales que desde su concepción clásica también han sido objeto de incorporación de matices contemporáneos como la «protección frente a una interceptación no razonable de las comunicaciones privadas por cualquier tipo de medio» ${ }^{91}$, todo bajo la máxima de igualdad ante la ley ${ }^{92}$. Una interesante atención se dedica a los derechos personales, así se regula el derecho a la privacidad ${ }^{93}$, a la propiedad ${ }^{94}$, la libertad de expresión $^{95}$, la libertad religiosa ${ }^{96}$, de reunión o asamblea ${ }^{97}$, de petición ${ }^{98}$. Mención aparte merece el derecho al aborto, que se regula desde un claro posicionamiento ideológico de los estados ${ }^{99}$. La negación del mismo avala la regulación constitucional de un «no derecho» ${ }^{100}$. En esa concepción negativa de los derechos se insertan las referencias constitucionales a la esclavitud ${ }^{101}$.

La atención subjetiva a diversos colectivos de personas con discapacidad aparece en las constituciones, fruto de las reformas posteriores a su redacción originaria. Así, la atención a personas sordas, mudas, ciegas o con problemas

identificando una serie de constituciones estatales en las que no se hallaban expresamente protegidas. Inicialmente se introdujo en California, Colorado — art. II, \$16 a, introducida en 1992), luego en Montana — donde el Tribunal Supremo de Montana lo anularía por vulnerar el requisito de voto por separado con otras enmiendas_-, Dakota del Sur, Dakota del Norte, Illinois, Ohio, Georgia, Hawaii, Idaho y Nevada.

90 Art. I, § 8. Const. de Ohio.

91 Art. I, § 12, Const. de Florida (incorporado en 1982).

92 Art. I, § 2 de la Const. de Michigan.

93 Art. II, § 8, Const. de Arizona.

94 Además de un derecho genérico a la propiedad, nos encontramos con explicitaciones subjetivas del mismo, como la protección expresa del derecho a la propiedad de los extranjeros o de las mujeres — con carácter previo a su matrimonio- (arts. I, $\$ 34$ y $§ 209$, de la Const. de Alabama).

95 Art. I, § 6, Const. de New Jersey.

96 Art. I, § 7, Const. de Ohío. («Derecho natural e irrevocable de adorar al Dios Todopoderoso según los dictados de su propia conciencia»). Se inserta en un derecho más amplio que es el de la libertad de conciencia.

97 Art. I., § 18, Const. de New Jersey.

98 Art. I, § 21, Const. de Wyoming.

99 En Arkansas la enmienda 68 a su constitución establece que no se dotarán fondos públicos para financiar las prácticas de aborto, con la salvedad de la necesidad de salvar la vida de la madre.

100 West Virginia, (art. VI, secc. 57). O la santidad de la vida por nacer reflejada en la reforma de la Const. de Alabama. El 6 de noviembre de 2018. Ha tenido su continuidad en la Ley 314, de 15 de mayo de 2019, en la que se prohíben todos los abortos en el estado, con la salvedad de aquellos compatibles con un riesgo serio para la salud de la madre. Human Life Protection Act, (https://legiscan.com/AL/text/HB314/id/1980843).

101 art. I, secc. 21 de la Const. de Utah, que sin embargo sigue dejando un espacio libre para la esclavitud como recurso de castigo por la comisión de un delito. Sorprende que hasta febrero de 2019 no se haya iniciado un proceso de reforma para suprimir esa referencia que se elaboró recurriendo a un espacio habilitado por la XIII. ${ }^{a}$ Enmienda de la Constitución que establecía que «Ni en los Estados Unidos ni en ningún lugar sujeto a su jurisdicción habrá esclavitud ni trabajo forzado, excepto como castigo de un delito de que el responsable haya quedado debidamente convicto/culpable». En el debate se justificó esa pervivencia como recurso a la escasez de mano de obra, pero se asumió el tono obsoleto del precepto en este momento y su no significación para reflejar el carácter del Estado de Utah.

Art. I $§ 34$ Const. de Oregón, que prohíbe la esclavitud y el trabajo involuntario, con la salvedad de su consideración como el castigo de un crimen. 
mentales se refleja en las constituciones, creando no un derecho subjetivo, sino una habilitación al legislador para que actúe atendiendo a esos ciudadanos, promoviendo su educación y una atención social más digna ${ }^{102}$.

Los derechos políticos, en particular el derecho al voto y el sufragio ${ }^{103}$ son objeto de gran atención por las constituciones ${ }^{104}$. En ocasiones, su literalidad se aparta de la ubicación en la carta de derechos constitucional y se ubica en la parte orgánica al regular el poder legislativo ${ }^{105}$. Este reconocimiento constitucional al derecho de sufragio también alberga una dimensión ideológica importante al introducir modulaciones en este derecho que tienen un claro mensaje político, como la potestad de requerir a los votantes un dominio razonable de la lengua inglesa, oral y escrita (art. II, § 6 Constitución de South Carolina).

Entre los derechos sociales destaca el atento papel que se ha dispensado a la educación ${ }^{106}$, la salud ${ }^{107}$ y a los derechos laborales y sindicales ${ }^{108}$. Su inserción suele aparecer de forma singularizada, fuera de los catálogos de derechos con los que se abren las constituciones estatales. En el ámbito de la salud ha cobrado una dimensión mediática el uso médico de la mariguana, inicialmente legalizada en California en 1996, y reflejada constitucionalmente en Nevada y Colorado ${ }^{109}$. La constitucionalización de la prohibición de fumar en lugares cerrados (Florida) ${ }^{110}$ y la aplicación de las tasas del tabaco para financiar fundaciones protectoras de la salud (Oklahoma) ${ }^{111}$ también ha tenido una recepción constitucional, así como la sanción de la mala praxis médica y la consiguiente responsabilidad (Florida) ${ }^{112}$.

102 Art. XI-I (2) Const. de Oregón, «multifamily housing for elderly and disabled». Art. XI § 1, Const. de Arizona, establece el mandato constitucional de elaborar leyes educativas que presten especial atención a personas sordas y ciegas. Sobre los mandatos de las constituciones estatales en materia educativa, véase PARKER, E., «Constitutional obligations for public education», Education Commission of the States, marzo 2016 (https:// www.ecs.org/wp-content/uploads/2016-Constitutional-obligations-for-public-education-1.pdf).

103 Art. II, § 5 Const. de California.

104 V. gr. Const. de Missouri, Art. I, Sección 25. «Que todas las elecciones serán libres y abiertas. y ningún poder, civil o militar, deberá interferir en ningún momento para impedir el libre ejercicio del derecho de sufragio».

105 Así, en la Const. de Utah, donde se regula el voto secreto y el uso de máquinas electorales, siempre y cuando respeten ese secreto al voto. (V. gr. Artículo IV, Sección 8.

106 Art. VIII, Const. de Maine.

107 TARr, A., «Federalism and the health care in the United State», REAF, núm. 14, octubre 2011, p. 17.

108 Destaca la regulación constitucional de un salario mínimo para mujeres y menores en el art. XVI, secc. 8 de la Const. de Utah.

109 Art. IV, § 38, Const. de Nevada (regula el uso del cannabis para fines médicos dentro del artículo IV dedicado al poder legislativo) y art. XVIII, $\S 16$, Const. de Colorado (dentro de un título miscelánea, recoge el uso personal de la mariguana, declarándola legal para las personas mayores de 21 años y sometiéndola a un régimen fiscal similar al tabaco. El 6 de noviembre de 2018 se aprobaría en el Estado de Missouri la «enmienda 2» relativa a la inserción en la Constitución de la legalización de la mariguana con fines médicos, aplicándose un impuesto a sus ventas del $4 \%$, ingresos fiscales que se asignarán a los servicios de salud para los veteranos de guerra.

110 Art. X $\$ 20$ y 27, Const. de Florida.

111 Mccaffree, D., «A Brief History of the Tobacco Settlement in Oklahoma» (https://www.ajpmonline.org/article/S0749-3797(14)00508-X/pdf)

112 Art. I § 26 Const. de Florida. 
Los derechos de tercera generación hallan un protagonismo en el constitucionalismo estatal de la mano de su inserción a través de sucesivas reformas. Así, la mayoría de constituciones estatales ha insertado la protección del interés público sobre los recursos naturales y medioambientales, aunque con interesantes diferencias, desde una mera autorización al legislativo para aprobar leyes medioambientales $^{113}$, hasta la gestión de un procedimiento para la preservación de la vida salvaje, el agua o de diversos recursos naturales ${ }^{114}$. Desde la protección inicial en las primeras constituciones de la caza y la pesca (Vermont, 1777, Rhode Island 1844, California 1910) se ha evolucionado hacia la reciente introducción de enmiendas constitucionales protectoras de los animales ${ }^{115}$.

La propia cultura política del estado se hace un hueco marcado en el catálogo de derechos constitucionales. Así, Louisiana destaca por la consideración del derecho a llevar armas como un «derecho fundamental» (art. I, secc. 11) ) $^{116}$ o el derecho a contraer matrimonio exclusivamente entre un hombre y una mujer (art. XII, secc. 15), que tras su incorporación a la constitución sería declarado inconstitucional como consecuencia de la sentencia Obergefell v. Hodges, 135 S.Ct. 2584 (U.S. 2015); la prohibición de la poligamia o de los matrimonios múltiples «forever prohibited» (art. 3 de la Constitución de Utah) o la reivindicación de la lengua inglesa como signo cultural ${ }^{117}$. También la «ideología política» en la más tosca acepción de la misma vinculada al enfrentamiento ideológico, ha tenido su reflejo constitucional. Así, como reacción a la Affordable Care Act (2010), popularmente conocido como «Obamacare», algunas constituciones (Arizona, Oklahoma) introdujeron, en una franca actitud contestataria y de rechazo a la misma, la prohibición de aprobar leyes que requieran a cualquier persona, empleador o proveedor de servicios médicos que participe en cualquier programa de atención médica ${ }^{118}$.

La reforma constante de las constituciones estatales ha permitido su incorporación a la corriente reguladora de derechos de nueva generación, cuarta generación, como la investigación con embriones humanos células embrionarias ${ }^{119}$, la presencia de las nuevas tecnologías en la canalización y adopción de decisiones oficiales ${ }^{120}$, la

113 Art. IV, § 52, Const. de Michigan.

114 Art. XVI de la Const. de Oklahoma, crea el Departamento para la conservación de la vida natural. Art. IV § 20, Const. de California. Thompson, B., H., «The environment and natural resources», TARR, A., State constitutions for the twenty first century, op. cit, p. 307.

115 Art. XVIII $\S 12$ b, Const. de Colorado.

116 Aparece en un elevado número de constituciones. Const. de California, art. II, $\S 13$.

117 Art. XVIII de la Const. de Arizona, el inglés como lengua oficial. También en las constituciones de California, Colorado u Oklahoma se encuentran disposiciones similares. La regulación del español tiene su espacio en constituciones como la de Nuevo México, art. X § 10, que consolida el derecho a la educación en español.

118 Art. 27 § 2, Const. de Arizona (a los efectos de preservar la libertad de los ciudadanos de Arizona de participar en un programa de salud). Con idéntica redacción, el art. II-37, B. 1, de la Const. de Oklahoma.

119 Art. I secc. 27 Const. de Michigan.

120 TASLitz, A., «The fourth amendment in the twenty-first century: technology, privacy, and human emotions", Law and contemporary problems. Enduring and Empowering: The Bill of Rights in the Third Millennium, Volume 65, Number 2 (Spring 2002), p. 161. 
adaptación del clásico derecho personal a la privacidad a la nueva coyuntura de intrusión desde los poderes públicos, configurados como auténticos derechos subjetivos vinculados a políticas públicas estatales ${ }^{121}$, entre los que se destaca uno de los derechos más reivindicativos de la nueva centuria, el derecho al agua ${ }^{122}$. Sin embargo este futurible no acota el reconocimiento constitucional de derechos, que se deja abierto en su literalidad asumiendo que su relación no exime la consideración de otros derechos no enumerados expresamente ${ }^{123}$, una especie de regulación de derechos implícita y prospectiva.

Tras este análisis, podemos sostener que el conjunto de estos derechos estatales es, con diferencia respecto al resto del contenido de las constituciones, el mejor crisol en el que se refleja la cultura de un estado, sus valores fundamentales y sus aspiraciones y preocupaciones, la idiosincrasia constitucional, no en vano, Emily Zackin, reconoce que el estudio de estas constituciones ayuda a realizar mejores interferencias entre los derechos americanos y los ideales americanos ${ }^{124}$.

\section{3. Parte orgánica}

A diferencia de la concepción funcional de la separación de poderes en la constitución federal, donde se regula de un modo indirecto, al derivarse de la atribución de potestades que se realiza a los distintos órganos articulados en los tres primeros artículos, las constituciones afrontan de modo directo y explícito la separación de poderes.

El reflejo de la separación de poderes en las constituciones estatales pasa por analizar el tríptico de los mismos topográficamente en su ubicación de modo inmediato tras la parte dogmática ( $v . g r$. Constitución de Arkansas). Una singular excepción a este patrón general se halla en la Constitución del Estado de Mississippi que regula en su primer artículo la separación de poderes, anteponiéndola, incluso, a las declaraciones de derechos.

Procesalmente, resulta llamativo cómo las constituciones estatales regulan el procedimiento legislativo e incluso el iter de elección de parlamentarios (v. gr. art. V de la Constitución de California). Estas limitaciones procesales no aparecieron en los primeros momentos de redacción de las constituciones estatales, sino que fueron una respuesta a la creciente desconfianza, percibida como «abusos de los

121 Art. XI, secc. 2, Const. de Illinois.

122 Art. 17, Const. de Arizona.

123 Art. I secc. 24 de Louisiana. «Derechos no enumerados. Sección 24. La enumeración en esta constitución de ciertos derechos no podrá negar o menospreciar a otros derechos de los ciudadanos, a título individual, del estado». En el mismo sentido, art. 2, secc. 29 Const. de Arkansas; art. I, § 36, de la Const. de Alabama, que se describe como «construcción de la declaración de derechos» o el art. I $\$ 33$ de la Const. de Oregón «enumeration of rights not exclusive».

124 ZACKIN, E., Looking for rights in all the wrong places. Why State Constitutions contain America's positive rights. Princeton, Princeton University Press, 2013, p. 48. 
legislativos estatales» ${ }^{125}$. Es importante que en ese procedimiento de tramitación la ley resultante no se distancie de su propósito original, un reto para legislativos en los que confluyen intereses muy confrontados (art. III, secc. 1 Constitución de Pensilvania) y que el resultado de las votaciones se refleje en los diarios oficiales (art. II, secc. 9 Constitución de Ohío). El sustrato de este planteamiento se expresaría en positivo como una apuesta por la transparencia, en negativo sería la permanente y profunda desconfianza hacia los legisladores estatales.

Orgánicamente el legislativo estatal es bicameral, integrado por un Senado y una Asamblea ( $v . g r$. art. IV, secc. 1, Constitución de California), bicameralismo que tiene su origen en Massachusetts ${ }^{126}$, desmarcándose Nebraska con su apuesta unicameral, con un legislativo formado por no más de cincuenta miembros y no menos de treinta (art. 3, seccs. 1 y 6 de la Constitución de Nebraska de 1875). Por su parte, las Cámaras legislativas de los Estados varían enormemente. La horquilla fluctúa desde los veinte miembros del Senado en Alaska, hasta los 400 miembros de la Cámara de Representantes de New Hampshire, con lo que casi se asemeja a la federal de la que la separan solo 35 miembros. Tampoco existe un correlato con su respetiva población, puesto que California, con unos 37 millones de habitantes tienen un legislativo de 120 miembros, mientras que el citado Estado del noreste de Estados Unidos, el quinto más pequeño de la Unión cuadriplica prácticamente esa cantidad de representantes con poco más de un millón de habitantes. En el Senado de cada Estado, destaca Minnesota con 67 senadores $^{127}$. Las diferentes duraciones de sus mandatos y los exiguos periodos de sesiones son otro rasgo de los legislativos estatales diseñados en las constituciones.

El poder ejecutivo, definido como el poder de administrar y ejecutar las leyes aprobadas por el legislativo e interpretadas por el poder judicial, sigue en protagonismo formal al legislativo en la redacción de las constituciones. Las constituciones estatales regulan el poder ejecutivo desde una perspectiva funcional asociada, orgánicamente, a un elenco de funcionarios electos junto con el Gobernador y el Vicegobernador. A ellos se une la relación de una serie de órganos y agencias cuya regulación se remite a leyes de desarrollo constitucional. Este poder se haya descrito de modo ligeramente diferente en las distintas constituciones. Así, la Constitución de Idaho se refiere a «Executive Department» (art. IV) ${ }^{128}$, simplemente «executive» ${ }^{129}$, como en el art. V de la Constitución de California, o «Executive power» en el Capítulo II, secc 1, de la Constitución de Massachus-

125 Williams, R., «State constitutional limits on legislative procedure: legislative compliance and judicial enforcement», Publius. The Journal of Federalism, n. ${ }^{\circ}$ 17, 1987, p. 91.

126 Morey, W., "The first State Constitutions», Annals of the American Academy of Politics and Social Science, Vol. 4, sept. 1893, p. 12.

127 Libonati, M. E., «The legislative branch», TARr, G.A., State Constitutions for the twenty-first century. The Agenda of State Constitutional Reform, op. cit., pp. 37-65.

128 En el mismo sentido la Const. de Kentucky, seccs. 69-108; art. IV de la Const. de Wyoming; Art. VI de la Const. de Arkansas; art. IV de la Const. de Colorado.

129 Art. V de la Const. de Mississippi; Art. V de la Const. de Wisconsin. 
sets. Orgánicamente el poder ejecutivo se plasma en la figura del Gobernador, del Vice Gobernador y de un Fiscal General, a los que se agregan diferentes oficinas y agencias. La duración de su mandato, por lo general de cuatro años, emulando la configuración presidencial del inicio del mismo en ese trabalenguas que se ilustra con el primer lunes posterior al segundo miércoles de enero siguiente a su elección, recogido en la Constitución de West Virginia. Entre sus potestades destacamos el veto gubernamental a la legislación ${ }^{130}$.

En el caso del poder judicial, llama la atención que ha sido objeto de la misma minuciosidad con la que se contemplan otros apartados de las constituciones. Así, constituciones como la de California llegan a regular el procedimiento por el que los jueces pueden emitir un voto particular en las sentencias. (art. VI, secc. 14). Cada Estado tiene su propia organización judicial ${ }^{131}$, estructurándose en dos o tres niveles en función de cada estado ${ }^{132}$. En la cima de la pirámide judicial estatal se sitúa un Tribunal Supremo, denominado en otros estados con diferentes expresiones como en Connecticut Court of errors.

\section{V.4. Otros contenidos. Las políticas públicas en sede constitucional}

Marcando una distancia considerable respecto a la configuración de la constitución federal, las constituciones estatales se singularizan por prestar una especial atención a las políticas públicas, convirtiéndose en ocasiones en auténticos programas directrices de las actuaciones materiales de los estados. Los ámbitos materiales en los que estas actuaciones se proyectan son la educación, las infraestructuras, la creación de corporaciones y la financiación de todo ese elenco de políticas públicas que se consolidan constitucionalmente, al margen de la deriva política de los diferentes gobiernos estatales.

Conocer la vida y la personalidad de cada estado puede lograrse a través del análisis de su constitución estatal, que se convierte en un espejo de su sociedad y de sus preocupaciones. Ese aspecto positivo, tiene un envés que se ha hecho notar en las primeras líneas. Esta regulación dispersa, contenidos impropios, a veces incoherente —que ha llevado sin reparo a alguna constitución a habilitar un título designado como «disposiciones diversas», Arkansas (art. 19); California (art. 20)_ y en muchas ocasiones impropia de una constitución, hasta el punto

130 Williams, R. F., The law of the american state constitutions, op. cit, p. 306

131 Cfr. Márquez Piñero, R., El sistema jurídico de los Estados Unidos de América, México, Universidad Autónoma de México, Instituto de Investigaciones Jurídicas de la UNAM, 1994, p. 36.

132 Las constituciones estatales han optado por tres formatos en la articulación del poder judicial: un tribunal (Michigan), un modelo de múltiples niveles (un tribunal supremo, unos tribunales intermedios de apelación, un tribunal con carácter general y otros tribunales especializados (Indiana) o un modelo en el que cada órgano judicial se regula de modo separado. TARr, G. A., «The judicial branch», TArr, G.A., State Constitutions for the twenty-first century. The Agenda of State Constitutional Reform, op. cit., p. 90. 
de peligrar la consideración de tal distinción, es, paradójicamente, una de las fortalezas del constitucionalismo estatal. La libertad para cazar, pescar y poner trampas (art. I secc. 27, Constitución de Louisiana); la regulación de las carreras de caballos y de las apuestas en Arkansas (enmienda 46, Constitución de Arkansas); la legislación sobre los casinos de la ciudad de Atlantic City (art. Art. IV Secc. 7 $\mathrm{D}$, Constitución de New Jersey); la protección de los veteranos de guerra en Kosovo, Afganistán e Iraq, para los que se habilita un fondo de ayuda económica (constitución de West Virginia, enmienda 17), que en reformas previas se había gestionado para los veteranos de Corea o Vietnam o los denominadas «caminos hacia la prosperidad», que habilita la emisión de deuda a los efectos de articular unos fondos públicos para la construcción de autopistas, carreteras y puentes en el Estado (Constitución de West Virginia, enmienda 18).

En este apartado deseamos hacer referencia a uno de los contenidos más relevantes de las constituciones estatales que entronca con la propia naturaleza de las mismas. Si el Bill of Rights de la Constitución federal, las 10 primeras enmiendas, podría adscribirse a una concepción negativa de la regulación de los derechos, las constituciones estatales ofrecen en su mayoría una plasmación positiva de los mismos, con la consiguiente carga de atribuciones funcionales a los gobiernos estatales, lo que indiscutiblemente se traduce en una necesidad de gasto, consecuentemente con una mayor presión fiscal y necesidad de endeudamiento. Si a esta realidad entroncamos la monitorización ciudadana de las mismas, que veremos en el siguiente epígrafe en lo referido al impulso y ratificación de los procesos de reforma, el resultado es una tensión entre presión pro-gasto y restricción al mismo. La conocida como Proposición $13^{133}$, aprobada en California en 1978, ha marcado el inicio de la vigente era constitucional que ilustra meridianamente esa tensión, entre incremento funcional y restricción de gasto y entre profesionalización constitucional y monitorización ciudadana.

En esa tesitura las constituciones se han debatido entre apostar por una necesaria presión fiscal (directa —educación — o indirecta — derechos de la negociación colectiva-) y por una, reclamada popularmente, restricción fiscal que se articula desde tres actuaciones: límites a la deuda, límites impositivos y al gasto y equilibrio presupuestario ${ }^{134}$.

Los límites a la deuda que están presentes en la casi totalidad de las constituciones estatales determinan bajo qué condiciones el estado puede endeudarse $\mathrm{e}^{135}$. Algunos estados prohíben totalmente la deuda ${ }^{136}$; otros imponen límites a la can-

133 Kemp, R.L., «California's Proposition 13: A One-Year Assessment», State E Local Government Review, Vol. 14, No. 1 (Jan., 1982), pp. 44-47.

134 Primo, D.M., State Constitutions and Fiscal Policy, Washington, George Mason University, 2016, p. 15.

135 Briffault, R., «State and local finance», TARr, G.A., State Constitutions for the twenty-first century. The Agenda of State Constitutional Reform, op. cit., pp. 215-216.

136 Art. X § 5, Const. de Indiana (prohíbe la deuda estatal con la excepción de afrontar déficits casuales en los ingresos, repeler una invasión, suprimir una insurrección o financiar la defensa del estado. En el mismo 
tidad de deuda en que el estado puede incurrirr ${ }^{137}$; en otras constituciones hallamos la conexión de la deuda a la obtención de determinados ingresos ${ }^{138}$; también se habilitan límites procesales que instan a apelar a su sometimiento al escrutinio popular ${ }^{139} \mathrm{o}$ a mayorías cualificadas en las cámaras. Un grado supremo de restricción se alcanza cuando se combinan ambos límites, los objetivos y los procesa$\operatorname{les}^{140}$. La eficacia de estas opciones parece apuntar como más resolutivos, en términos de reducción de la deuda, aquellos que optan por remitir su autorización a «supermayorías» o a conectarla a los ingresos ${ }^{141}$.

Por su parte la limitación en el gravamen impositivo a los ciudadanos y en el gasto, conocido con el acrónimo TELs (Tax and Expenditure Limits), se centra en restringir la capacidad impositiva y los niveles de gasto de un estado. Las opciones varían, centrándose en la limitación a los impuestos o a los gastos, a partir de fórmulas diferentes el crecimiento de la población, la inflación o los ingresos personales. Estados como Texas, Arkansas o Indiana han incluido esta medida restrictiva en sus constituciones ${ }^{142}$

Finalmente, la apelación de las constituciones a la sincronización entre ingresos y gastos, se ha buscado bien de modo directo, bien de modo mediato, limitando o prohibiendo la deuda. Estos mecanismos, que tratan de fortalecer la confianza en el sistema público y la fe constitucional, chocan con una realidad donde los gobiernos, apurados por sus compromisos políticos buscan circundar todas esas limitaciones ${ }^{143}$.

\section{LA REVISIÓN Y REFORMA DE LAS CONSTITUCIONES ESTATALES}

La razón de ser de la revisión y reformas ${ }^{144}$ de las constituciones estatales radica, fundamentalmente, en la adecuación de su contenido a la evolución y a la

sentido, el art. X § 4 de la Const. de West Virginia, que agrega como excepción afrontar la necesidad del pago de responsabilidades estatales previas, lo que viene a ser una contradicción con la prohibición inicial.

137 Por ejemplo, el art. IX $\S 5$ de la Const. de Arizona, que limita la deuda total del estado a 350.000 $\$ ; \$ 49$ de la Const. de Kentucky, con un límite de 500.000 \$ (un texto que procede de 1891); art. VIII § 1 de la Const. de Ohio (750.000 \$) o el art. VI $\$ 16$ de la Const. de Rhode Island, con $50.000 \$$.

138 Art. VII $\S$ IV, par. II, de la Const. de Georgia limita la deuda al 10\% de los ingresos obtenidos por el estado; art. VIII $\S 1$ de la Const. de Washington, lo conecta al 9\% de la media de ingresos de los tres años fiscales precedentes. En el mismo sentido, las Constituciones de Hawaii (art. VII §13 o Const. de Nevada (art. VIII § 1).

139 Art. X § 13, de la Const. de South Carolina.

140 Art. IX $\$ 15$, de la Const. de Michigan.

141 Kiewiet, R., «Constitutional Limitations on Borrowing: An Analysis of State Bonded Indebtedness» Journal of Law, Economics, E Organization, Vol. 12, No. 1 (Apr., 1996), p. 62.

142 KinCAID, J., «Early State history and constitutions», op. cit., p. 256.

143 Bunch, B., «The effect of constitutional debt limits on state governments' use of public authorities», Public Choice, January 1991, Volume 68, Issue 1-3, p. 57.

144 Por revisión entendemos la sustitución íntegra de una constitución por otra. Por reforma, la alteración del texto de la misma por agregación, sustracción o modificación de alguno de sus preceptos. En las 
atención a demandas sociales, económicas, políticas y culturales, en constante evolución, de los ciudadanos de cada estado. De acuerdo con Lutz, aparte de potenciar la idea de soberanía popular, en el consenso americano de finales del siglo XVIII, el proceso de reforma constitucional se basaba en otras premisas: la imperfecta, pero educable naturaleza humana; la eficacia del proceso deliberativo y la necesidad de diferenciar el orden constitucional de los procesos legislativos $\operatorname{ordinarios}^{145}$. Este ritmo parece ser supersónico a la luz del trepidante movimiento reformador de las constituciones estales americanas ( «los estados americanos han propuesto 354 constituciones, 250 convenciones y ratificado 146 constituciones con, al menos, 5.900 enmiendas» $)^{146}$.

Esta vocación, casi obsesión, de los estados de reformar, "remendar» (tinkering $)^{147}$, las constituciones estatales quiebra la propia filosofía reformista que vincula la misma al paso del tiempo. Las consecuencias de esa promiscuidad reformadora se dejan notar en las mismas constituciones y en su adicción a los cambios que no ceja de autoalimentarse ${ }^{148}$. Regulaciones detalladas, minuciosidad, carácter perentorio de las materias constitucionalizadas y reforma son elementos que se integran en una concepción sui generis de las constituciones estatales que halla su punto de inflexión en su hiperflexibilidad ${ }^{149}$ y en un resultado que concluye en constituciones excesivamente largas y con una marcada orientación política $^{150}$.

El régimen jurídico que determina los procedimientos de reforma de cada constitución ofrece un panorama complejo, con denominadores comunes, circunstancia que se acentúa si atendemos a una práctica que, a su vez, se ha distanciado de la literalidad de las propias constituciones. Es decir, la tradicional principal diferencia del constitucionalismo estatal frente al constitucionalismo federal en atención a la modificación constitucional, _ la opción federal por la mutación, que apuesta por afrontar los principales cambios del diseño original de la federación, como la ampliación del predominio federal o la expansión del

constituciones estatales se regula el proceso de revisión de modo específico en los siguientes estados: Alaska, Alabama, California, Colorado, Florida, Hawaii, Idaho, Illinois, Kansas, Lousiana, Michigan, Missouri, Montana, Nevada, New Hampshire, North Carolina, Oklahoma, Oregon, Rhode Island, South Carolina, South Dakota, Utah y Virginia.

145 LuTz, D. S., «Toward a theory of constitutional amendment», The American Political Sciencie Review, vol. 88, n. ${ }^{\circ}$, jun. 1994 , p. 356.

146 Woodward-Burns, Robinson, American Reconstitution: How The States Stabilize American Constitutional Development, (2017). Publicly Accessible Penn Dissertations. 2643., p. 4. https://repository.upenn. edu/edissertations/2643

147 TARr, A., Understanding State Constitutions, op. cit., p. 24.

148 Así, la enmienda 765 de la Const. de Alabama, es «Amendment to amendment 649», referido a la exacción de un impuesto con fines de apoyar la lucha contra incendios. En el mismo sentido las enmiendas $731,728,670,426,762$ o 763 .

149 DinAN, J., «The earth belongs always to the living generation: the development of state constitutional amendment and revisión procedures», The Review of Politics, Vol. 62, n. . 4, Fall 2000, pp. 645-674.

150 Hammon, C.W., «State constitutional reform: Is it necessary?», Albany Law Review, vol. 64, 2011, p. 1327. 
protagonismo presidencial, implementados al margen de los cauces formales de reforma, frente al formalismo reformista estatal apegado en su práctica a la literalidad procesal de las constituciones ${ }^{151}$ _ , podría minorarse si los procesos de reforma de las constituciones estatales se liberan, como parece ser, de lo pautado en la literalidad de las mismas ${ }^{152}$.

\section{VI.1. Impulso}

\section{A partir de la regulación constitucional de los procedimientos de reforma podemos hallar interesantes matices ${ }^{153}$. Así, en lo que se refiere al impulso}

151 La consideración de la constitución federal como símbolo de la unidad nacional hace que se extremen las cautelas de un potencial proceso de reforma de la misma, formalizado solo en veintisiete enmiendas, para el que se necesitan 39 gobiernos, el federal y 38 gobiernos estatales, algo complicado de alcanzar. El artículo V de la Const. de los Estados Unidos establece solo dos mecanismos para afrontar la reforma constitucional: Las enmiendas pueden ser propuestas por 2/3 de ambas cámaras del Congreso, y luego ratificadas por $3 / 4$ de los estados, ya sea por sus legislativos o a través de convenciones. Igualmente, el impulso puede ejercerse por $2 / 3$ de los legislativos estatales.

152 Estas mutaciones contra constitutionem, se pueden ilustrar en las prácticas de estados como Alabama, Nebraska y Ohío, donde se introdujeron cláusulas en las papeletas de votación que permitía rechazar una propuesta de reforma eliminando de la papeleta de votación la declaración de aprobación de la misma que se introducía en la misma (Alabama), mientras que en Nebraska y Ohío, el voto a un partido suponía el apoyo a las reformas constitucionales apoyadas por este, sin necesidad de ulterior ratificación expresa de las mismas. Incluso los tribunales han encontrado en las constituciones facultades implícitas que avalan la convocatoria de convenciones para reformar las constituciones. Por ello, constituciones como Missouri, que expresamente reclama su control del proceso de reforma «esta constitución debe ser reformada solo como aquí se establece» (art. XII, §1). Benjamin, G., «Constitutional amendment and revisión», TARR, A., State constitutions for the twenty first century, op. cit, pp. 178-179.

153 Normalmente un artículo final en cada constitución estatal se dedica a regular el proceso de reforma. De modo excepcional podemos encontrar referencias a la reforma constitucional en el articulado referido al poder legislativo o un artículo diferente referido a la participación ciudadana (North Dakota, donde el art. III, § 9 que regula la iniciativa popular para la reforma constitucional se ubica en el artículo intitulado «poderes reservados al pueblo» y en el art. IV,$\S 16$, que regula la iniciativa legislativa de la reforma constitucional). Alabama, art. XVIII, § 284-287 o (En esta constitución las enmiendas se ubican como anexos a la misma, al modo y manera de la constitución federal. Hasta el momento la última es la enmienda 772, referida a la promoción del desarrollo económico e industrial por una Comisión del Condado, con lo que la convierte en la constitución más larga con 388.882 palabras, seguida de Texas con 86.936, según los datos de la Conferencia Nacional de Legislativos estatales); Alaska, art. XIII; Arizona, art. 21; Arkansas, art. 19, § 22; California, art. 18, §1-4; Colorado, art. XIX; Connecticut, art. XII; Delaware, art. XVI; Florida, art. XI, §1-7; Georgia, art. X; Hawaii, art. XVII; Idaho, art. XX; Illinois, art. XIV; Indiana, art. 16; Iowa, art. X; Kansas, art. 14; Kentucky, §§ 256-263 («mode of revisión», aunque bajo ese epígrafe también regula el procedimiento de reforma); Louisiana, art. XIII; Maine, art. X; Maryland, art. XIV; Massachusetts, art. XLVIII; Michigan, art. XII; Minnesota, art. IX; Mississippi, art. 15, § 273- llega a regular hasta el modelo de papeleta en las votaciones-; Missouri, art. XII; Montana, art. XIV; Nebraska, art. XVI; Nevada, art. 16; New Hampshire, art. 100; New Jersey, art. IX; New Mexico, art. XIX, New York, art. XIX; North Carolina, art. XIII; North Dakota, art. III, § 9; art. IV, §16; Ohio, art. XVI; Oklahoma, art. XIV; Oregón, art. XVII; Pennsylvania art. XI; Rhode Island, art. XIV; South Carolina, art. XVI; South Dakota, art. XXII; Tennessee, art. XI; Texas, art. 17; Utah, art. XXII; Vermont, § 72; Virginia, art. XIII: Washington, art. XXIII; West Virginia, art. XIV; Wisconsin, art. XII; Wyoming, art. 20. 
reformista, los estados han articulado una diversidad de sujetos promotores de la reforma. El más habitual apunta a las legislaturas de los estados, ya sea por mayoría simple, ya sea por mayoría cualificada, con diferentes quórums 3/5, 2/3 o 3/4. El grado de dificultad se eleva cuando se requiere que sean dos legislaturas sucesivas las que promuevan tal impulso reformador ${ }^{154}$. La descripción de este proceso de impulso de reforma por el legislativo aumenta, aún más, su complejidad al verificar que su opción no es unívoca en cada una de las cincuenta constituciones estatales, sino que en alguna de ellas se ofrecen métodos alternativos para su materialización (Connecticut, Hawaii, New Jersey y Pensilvania), ora mayorías simples con una doble tramitación, ora mayorías extraordinarias con una sola, que por ejemplo en Pensilvania se acota a situaciones excepcionales de emergencias. Las enmiendas pueden ser presentadas por cualquier miembro de las cámaras. En New Jersey se requiere una audiencia pública antes de la votación por el cuerpo legislativo. Cuando se requieren dos tramitaciones se habilita un lapso de tiempo entre ellas. Otro requisito formal es que cada una de estas votaciones se refleje en los boletines de las Cámaras, aspectos cuyo incumplimiento habilitaría a la anulación de la reforma por parte de los tribunales. También cabe la posibilidad de retirar las enmiendas presentadas, con requisitos similares a los de su introducción, por ejemplo, en California, o bien o quórums más agravados como en Illinois (3/5). Este proceso ante el legislativo se haya monitorizado por el Secretario de Estado o por el Subgobernador (Liutenant Governor) ${ }^{155}$, que preparan el contenido de las papeletas de votación que se someten a escrutinio electoral o actuando como fedatarios públicos del proceso ${ }^{156}$, la razón de ser estriba en evitar en que se introduzca algún sesgo distorsionador a los votantes en las papeletas, alterando fraudulentamente el apoyo a la reforma ${ }^{157}$.

Las comisiones constitucionales, la conformación de un grupo de expertos que elaboren un elenco de propuestas de reforma constitucional, designados por el legislativo o por el ejecutivo, son también otra opción impulsora de la reforma constitucional estatal. Elaboran propuestas de reforma constitucional que remiten a los ciudadanos. Así, el art. XI, secc. 2 de la constitución de Florida prevé este recurso a una comisión constitucional, Comisión de revisión constitucional,

154 Aquí la casuística es muy variada. Tras la aprobación de la iniciativa de reforma se requiere acudir a una elección general para su ratificación. Esa aprobación del legislativo puede ser por mayoría simple en cada cámara. En Massachussets la peculiaridad es que han de reunirse en sesión conjunta. En Delaware se requiere una aprobación por 2/3 de cada cámara. En Tennesse se exige mayoría en la primera tramitación legislativa, pero un apoyo de $2 / 3$ en la segunda tramitación legislativa. En Vermont se requiere mayoría simple en la cámara baja y mayoría de 2/3 en el Senado. En Carolina del Sur 2/3 de cada cámara en cada vuelta.

155 Art. XIII, §1, de la Const. de Alaska.

156 Una particularidad se encuentra en la Const. del estado de Nueva York, donde el Fiscal general tiene la obligación de trasladar su parecer sobre la concreta reforma constitucional dentro de los veinte días de su planteamiento.

157 Señala la Const. de Ohio, «The ballot language shall properly identify the substance of the proposal to be voted upon. The ballot need not contain the full text nor a condensed text of the proposal». Art. XVI, $\S 1$. 
de 37 miembros, cifrando una composición heterogénea en la que confluyen las propuestas de los tres poderes estatales (el Gobernador, el portavoz de la cámara; el presidente del Senado y el Presidente del Tribunal Supremo). También en este estado destaca una comisión especial, Comisión de reforma impositiva y presupuestaria, integrada por 27 miembros. Otros estados, como Nuevo México y Utah, también disponen de dichas comisiones.

La Convención constituyente es también una fórmula generalizada ${ }^{158}$. El procedimiento específico para confeccionar una convención constitucional o constituyente varía, pero su estructura se acomoda al siguiente patrón. La creación de una convención puede obedecer a tres impulsos, el del legislativo (Illinois y Nebraska, donde el 3/4 de los legisladores deben apoyarla, con necesidad de refrendo ciudadano, que no es necesario en South Dakota; 2/3 en otros estados o mayoría simple, pero ratificada en dos legislaturas sucesivas, como Lousiana). En este caso la convocatoria puede realizarse en cualquier momento, logrados los mencionados apoyos; el de los ciudadanos, como en Florida o de origen automático por mandato constitucional, cada veinte, diez, dieciséis (Michigan) o nueve (Hawaii) años. Pese a que los ciudadanos se presentan como los titulares de dicha potestad para impulsar la creación de una Convención, el impulso real se confiere a los partidos políticos o asociaciones de intereses que estimulan dicho proceso. Formalmente, se ha de presentar y registrar una petición para dicha creación que esté suscrita por un porcentaje significativo de ciudadanos. V. gr. un número de electores de, al menos, la mitad de los distritos o circunscripciones electorales para las elecciones legislativas del Estado y respecto al total del electorado en su conjunto. En el caso de Florida (art. XI, secc. 4) han de equivaler al $15 \%$ respectivamente de los votos emitidos en la última elección presidencial. Se busca, pues, una legitimidad territorial y otra poblacional. El siguiente paso toma como referente la elección general más próxima - con un mínimo espacio de tiempo que suele cifrarse en 90 días de antelación-en el que tal petición se trasladará al electorado, con una pregunta genérica del tipo «¿Debe celebrarse una convención constitucional?» El voto favorable de la mayoría de los electores da paso a un tercer estadio, que se vincula a la siguiente elección general en la que se procederá a elegir a los componentes de la convención constitucional, buscando un reflejo territorial, al que se agrega la designación de los funcionarios que han de incorporarse, y en cuya primera reunión han de fijar su reglamento de actuaciones, y un calendario de actuaciones para sus posteriores reuniones. Sus propuestas deben de formalizarse con anterioridad a la siguiente convocatoria electoral en la que serán sometidas a la votación ciudadana. En el caso del impulso reformador con origen convencional, este tiene poderes plenarios para afrontar la reforma o la

158 Las siguientes constituciones no prevén dichas convenciones: Arkansas, Indiana, Massachussets, Mississippi, New Jersey, North Dakota, Pennsylvania, Texas y Vermont. 
revisión, que ha de ser ratificada por los ciudadanos ${ }^{159}$, prohibiéndose expresamente el veto gubernamental a sus propuestas (Alabama, Hawaii y Georgia).

La reforma constitucional por iniciativa popular. Los estados también han incluido la posibilidad de conferir a sus ciudadanos la potestad de proponer reformas de la constitución ${ }^{160}$ que se remitirán directamente a ratificación de los ciudadanos o bien de modo mediato, tras su validación por los legislativos, como en los Estados de Massachusetts o Mississippi. Es en este tipo de iniciativa donde en algunas constituciones introducen una restricción a su ejercicio, excluyendo del mismo materias como reformas constitucionales que limiten el poder del gobierno para recaudar ingresos o desarrollar actuaciones con esa finalidad (art. XI, secc. 3 Constitución de Florida) o en materia religiosa, poder judicial o derechos protegidos (art. XLVIII, secc. 2 Constitución de Massachussets) o modificar la Carta de Derechos, el sistema de jubilación de los empleados públicos, la no afectación de los derechos de los trabajadores por su afiliación a sindicatos u organizaciones, el mismo proceso de iniciativa de reforma constitucional (art. XV, secc. 273, 5 (a-d) Constitución de Mississippi). En este supuesto de petición ciudadana de una reforma constitucional (para la que se requiere una serie de firmas $10 \%$ es lo más común) se suele requerir que la tramitación legislativa de la misma se acompañe de la elaboración de una memoria del impacto económico que ello puede suponer.

\section{VII.1.2. Tramitación}

La propuesta de reforma constitucional se tramita como una resolución legislativa que se someterá a consideración de los ciudadanos en la siguiente elección general o, de modo excepcional, en una elección específica, como hemos visto, que se adelanta a la misma si lo apoya un porcentaje elevado de miembros de los legislativos (3/4 de cada cámara en Florida). Tras ese refrendo ciudadano la reforma pasará a integrarse como parte de la constitución estatal.

Esta tramitación de los procesos de reforma no está exenta de límites, de carácter formal, material y territorial. Desde el plano formal, las constituciones acotan el número de enmiendas a tramitar en una sesión legislativa ${ }^{161}$, han de vincularse a la celebración de elecciones generales (Connecticut, Kentucky o New Hampshire) o especiales (West Virginia); ha de distanciarse la tramita-

159 Art. XIII, § 4, Const. de Alaska.

$160 \mathrm{~V} . \mathrm{gr}$. Art. 21, $\S 1$, de la Const. de Arizona que requiere que dicha petición popular esté firmada por un número de electores equivalente al $15 \%$ de los votos a la totalidad de los candidatos a gobernador en las pasadas elecciones generales. Art. 18, $\$ 3$ de la Const. de California.

161 En Arkansas el legislativo no pueden presentar a los electores más de tres enmiendas en un año. En Kentucky el límite es de cuatro; en Kansas de cinco o la limitación a reformar no más de tres artículos de la constitución en un año por parte de la Const. de Illinois que se eleva a seis en Colorado. 
ción parlamentaria de su sometimiento a votación, por lo general se habilita un periodo de tres meses, en el que se exige la publicación en medios de diferente ideología (Missouri) o que se divulgue por todo el Estado (Georgia, Arizona), con argumentos a favor o en contra (Idaho, Ohío) o se use el inglés y el español (Nuevo Méjico); han de votarse de modo separado cada una de las enmiendas, para evitar el «logrolling» ${ }^{162}$; un límite a una ulterior presentación en caso de que la propuesta inicial sea rechazada, desde el transcurso de dos elecciones generales en New Jersey al cómputo de cinco años en Pensilvania. Materialmente, los límites pueden ser absolutos, como al impulso legislativo de las reformas constitucionales se vinculan a la propia protección del principio de representación parlamentaria (Alabama) o relativos, exigiéndose elevados apoyos electorales cuando se tramiten reformas en materia de educación o derecho de voto (Nuevo México) o Florida (2/3, para la introducción de un nuevo impuesto). Finalmente, hay límites territoriales en el proceso de impulso legislativo y su pertinente ratificación electoral, desde la prescripción de Georgia del alcance general de las reformas constitucionales, al requisito expreso de Louisiana o Maryland de contar con el apoyo expreso de las unidades territoriales afectadas por la reforma.

\section{VII.1.3. Integración}

La entrada en vigor se vincula, por lo general a una ratificación popular positiva, con la excepción de estados como Delaware ${ }^{163}$. La ratificación de las reformas constitucionales se remite a los ciudadanos, cuya mayoría simple de votos es suficiente para validar tal proceso, sin tener en cuenta cuántos han votado (Alaska). Es decir, quienes efectivamente participen en dichas votaciones determinarán la aprobación de las reformas. Sin embargo, en otros estados se requiere una participación mínima, como Hawaii, donde el necesario que apoyen la reforma el $50 \%$ de los votantes en una elección general o el $30 \%$ de los registrados si es una elección especial. Es importante desmitificar este proceso de ratificación que no se puede vincular de modo automático al pleno control ciudadano de la reforma constitucional. La realidad apunta a un conocimiento limitado del contenido de las reformas, una escasa participación motivada en el desinterés o en la fatiga y hastío participativo lo que deriva en posturas incoherentes y contradictorias de los votantes ${ }^{164}$. Quizá lo más sencillo sería considerar que las reformas de las constituciones estatales forman parte del juego político.

162 En Oregón se concibe su presentación de modo concatenado o vinculado.

163 Art. XVI, §1 Const. de Delaware. Exige la aprobación de la reforma por 2/3 de los miembros de cada cámara.

164 Carrillo, D. (et. al.), «California constitutional law: direct democracy», Southern California Law Review, vol. 92, 2019, p. 607. 
A partir de ahí la efectividad de la entrada en vigor de la reforma se vincula al transcurso de una mínima vacatio ${ }^{165}$, en la que una autoridad certifique la validez de los resultados. Ex post, la habilitación del control judicial para supervisar la legalidad y constitucionalidad de los procedimientos de reforma se circunscribe en esencia a un «mandamus» que obliga al Tribunal a resolver una cuestión no atendida por otros tribunales o autoridades administrativas. En ese sentido, pudiéramos sostener que los jueces estatales se convierten, a diferencia de los jueces federales, en sujetos activos del proceso de reforma constitucional estatal, en cuanto freno de diferentes propuestas de reforma.

Los resultados del estudio empírico y comparado del proceso de reforma de las constituciones estatales norteamericanas han abrazado las siguientes conclusiones: la interacción de dos variables, la longitud de la constitución y la dificultad del proceso de reforma condiciona su concepción; la manipulación de estas dos variables llevaría a diseñar constituciones predecibles; existe una evidencia que conecta la tasa de reforma o enmienda con la probabilidad de que una constitución sea revisada o su tenga una mayor longevidad. Datos que llevarían a una ecuación deseable de tasa de reforma moderada a lograr mediante la combinación de un proceso legislativo complejo, intervención de los electores y un documento constitucional corto. Es decir, en términos de racionalidad es preferible la brevedad constitucional y un grado moderado de procedimiento de reforma ${ }^{166}$.

\section{LOS AVATARES DEL PROCESO CONSTITUCIONAL ESTATAL Y SUS ENSEÑANZAS PARA UN FUTURIBLE PROCESO DE FEDERALIZACIÓN Y CONSTITUCIONALIZACIÓN ESTATAL EN ESPAÑA}

El desequilibrio entre la atención que se ha prestado a la reflexión sobre el federalismo y su problemática y el análisis de la contribución de las constituciones estatales a reforzar o a minar dichos logros ha sido el marco en el que se ha insertado esta reflexión que concluye con dos grandes pensamientos, uno de teoría general constitucional y otro de carácter particular, focalizado en una aproximación prospectiva a la realidad española.

Diferentes argumentos avalan la necesidad de consolidar una teoría del constitucionalismo estatal, con unas características que la singularicen. Su origen se engarza en el análisis de los sistemas de constituciones estatales existentes, en este caso el norteamericano, desde los que se puede valorar su contribución a la capacidad de un sistema federal para integrar en un marco constitucional único diferentes intereses y comunidades políticas, su aportación a potenciar el pilar de

16530 días, por ejemplo, en Alaska. Art. XIII, $\S 1$.

166 LuTZ, D.J., «Toward a theory of constitutional amendment», op. cit., p. 366. 
libertad de los federalismos, contrarrestada por la necesidad de una estructura esencial común que faculte la operatividad del sistema, a la par que, se avance en conocer los potenciales riesgos y excesos que desde este constitucionalismo estatal pueden producirse. En consecuencia, una teoría constitucional estatal ha de incorporar un reto teórico y doctrinal que se elabore ex novo, a partir de su esencia que es el análisis de una serie de normas, tanto formales como informales, que protegen y definen la autoridad subnacional dentro de un sistema federal, desarrollando la independencia conferida a dicha estructura, a la vez que limitando el poder que la propia federación les otorga. Los matices vendrán en el plano dogmático, en el orgánico y en la concepción de la reforma y la revisión de estos textos, así como en sus relaciones con la constitución federal. Una nueva dogmática, una compleja doctrina, la de las constituciones estatales, se consolida en el marco del constitucionalismo del siglo XXI.

En el plano de un análisis prospectivo sobre el constitucionalismo español de la mano de una ulterior federalización del mismo, asumimos que la base del constitucionalismo estatal está formalmente articulada en sus trazos esenciales, tras la evolución implicada por las reformas estatutarias. Así, «in Spain, for example, are the regional «Autonomy Statutes» constitutions or not? They do seem to exhibit some of the atributes of constitution but that term is studiously avoided in Spain ${ }^{167}$. Sin embargo, hay una falla en la base que puede lastrar todo el proceso. Estamos refiriéndonos al profundo déficit de cultura federal en nuestro país. Partiendo de resaltar una cláusula de supremacía de la constitución federal respecto a las constituciones estatales y de una cláusula de garantía que afiance su independencia, la idea de unidad y diversidad, como un todo indisociable, tiene que impregnar los cimientos de ese proceso. Es preciso dotar de una legitimidad desde ese prius, al proceso legal de federalización y constitucionalización estatal. Llegados a ese punto, desde la experiencia norteamericana, cuáles son las principales líneas rojas. Dado que en España, estructuralmente, el federalismo tendría un carácter centrífugo, es preciso partir de un modelo constitucional estatal, insertable en la propia constitución federal, utilizable como parámetro de constitucionalidad de las nuevas constituciones. No compartimos la apuesta por un proceso «botton up», en el que los vigentes estatutos determinen la evolución federal, ni la existencia de leyes de habilitación que constriñan estas constituciones. Sí es necesario un control de la constitucionalidad de esas normas jurídicas que solo han de gestarse en los estados federados. Desde el punto de vista de su contenido es preciso no perder la esencia de su carácter constitucional, eludiendo la inserción de aspectos que deben formar parte de la legislación de desarrollo e incluso del ámbito reglamentario de la propia ejecución normativa. También, un

167 Williams, R. F. y TARr, G. A., «Subnational constitutional space: a view form the states, provinces, regions, länder and cantons», TARr, A., Williams, R.F., y MARKo, J., Federalism, subnational constitucions and minority rights, op. cit., p. 5. 
reto es concebir estas constituciones como elemento cultural de cada estado, pero no como un panfleto político y efímero de corrientes y propuestas, un motor de división, lo que las convertiría en referentes de una cultura federal degradada y distorsionada. Especialmente cuidadoso ha de ser el proceso de su reforma y la presencia en el mismo de los ciudadanos. La idea de las convenciones constitucionales, a celebrar protocolariamente en un periodo de tiempo marcado por la constitución, es una opción que se articula como antídoto a un estrés democrático que apunta a una fatiga colectiva. Así, en términos de racionalidad lo deseable son constituciones cortas y con procesos de reforma que potencien la participación ciudadana, pero que se dosifiquen en el tiempo.

Con todo ello afianzamos la tesis de la dimensión problemática de las constituciones estatales para el federalismo y la atención prioritaria que las mismas han de recabar en un proceso de federalización de un Estado. Es preciso clarificar su status en el sistema de fuentes, resaltar su dimensión normativa, su validez y eficacia, habilitar un espacio competencial a las mismas desde la Constitución federal, no prescindir de una estructura y unos principios comunes a las mismas garantizados por su lealtad a la Constitución federal y habilitarlas como espacios jurídicos donde regular los elementos singularizantes de un federalismo, por qué no asimétrico, que tiene como límites infranqueables la unidad y la igualdad.

$$
* * *
$$

\section{TITLE: State Constitutions. Mainly, American State Constitutions}

ABSTRACT: This article deals with a study of the state constitutions of the federal states, based on two premises: their diversity among the different federal states and their disregard by the doctrine and the citizens. Taking as reference the state constitutions of the North American states, it has been tried to clarify the legal position of the same in the system of sources and to know their vicissitudes from an analysis of the most relevant aspects of their content. As a final point, the state constitutions' amendment procedure is studied, a complex process in which the plurality of intervening actors stands out, as well as the variety of requirements in their processing and integration. This work is integrated in the need to know all the elements to be considered in a federalizing approach, beyond general and imprecise formulas.

RESUMEN: En este artículo se aborda un estudio de las constituciones estatales de los Estados federados, a partir de dos premisas: la diversidad de las mismas entre los diferentes estados federales y su postergación por parte de la doctrina y de los ciudadanos. Tomando como referencia las constituciones estatales de los estados norteamericanos se ha tratado de clarificar la posición jurídica de las mismas en el sistema de fuentes y de conocer sus avatares a partir de un análisis de los aspectos más relevantes de su contenido. Como punto final se ba analizado la reforma de las mismas, proceso complejo en el que destaca la pluralidad de actores intervinientes, así como la variedad de requisitos

KEY WORDS: state constitutions, guarantee clause, supremacy clause, enabling laws, constitutional conventions.

Palabras Clave: constituciones estatales, cláusula de garantía, cláusula de supremacía, leyes habilitantes, convenciones constitucionales.

FECHA RECEPCIÓN: 29.11.2018

FECHA ACEPTACIÓN: 29.07.2019 